\title{
Tundish Cover Flux Thickness Measurement Method and Instrumentation Based on Computer Vision in Continuous Casting Tundish
}

\author{
Meng Lu, He Qing, Xie Zhi, Yang Weimin, Ci Ying, Zhang Chuanyi, and Gao Hongliang \\ College of Information Science and Engineering, Northeastern University, Shenyang 110000, China \\ Correspondence should be addressed to Meng Lu; menglu1982@gmail.com
}

Received 10 April 2013; Accepted 2 July 2013

Academic Editor: Praveen Agarwal

Copyright (C) 2013 Meng Lu et al. This is an open access article distributed under the Creative Commons Attribution License, which permits unrestricted use, distribution, and reproduction in any medium, provided the original work is properly cited.

\begin{abstract}
Thickness of tundish cover flux (TCF) plays an important role in continuous casting (CC) steelmaking process. Traditional measurement method of TCF thickness is single/double wire methods, which have several problems such as personal security, easily affected by operators, and poor repeatability. To solve all these problems, in this paper, we specifically designed and built an instrumentation and presented a novel method to measure the TCF thickness. The instrumentation was composed of a measurement bar, a mechanical device, a high-definition industrial camera, a Siemens S7-200 programmable logic controller (PLC), and a computer. Our measurement method was based on the computer vision algorithms, including image denoising method, monocular range measurement method, scale invariant feature transform (SIFT), and image gray gradient detection method. Using the present instrumentation and method, images in the CC tundish can be collected by camera and transferred to computer to do imaging processing. Experiments showed that our instrumentation and method worked well at scene of steel plants, can accurately measure the thickness of TCF, and overcome the disadvantages of traditional measurement methods, or even replace the traditional ones.
\end{abstract}

\section{Introduction}

As the development of high-speed casting, tundish cover flux (TCF) is becoming the key material for continuous casting process, which has more and more important and irreplaceable roles on the quality of steel billet. The main functions of TCF are as follows: isolate the steel surface to prevent freezing, protect the steel surface from oxidation, absorb inclusions that are transported to the surface, maintain a low friction between steel shell and mold by lubrication, create an optimum heat transfer from steel to mold, and so on [1-4].

The melting point of TCF (about $1000 \sim 1150^{\circ} \mathrm{C}$ ) is lower than the temperature of molten steel (about $1500^{\circ} \mathrm{C}$ ). And the TCF is divided into three main parts according to the physical form, namely, liquid slag layer, sintered layer, and powder slag layer (shown in Figure 1). TCF is added on the top of the molten steel in the continuous casting mold, which partially melts and forms a liquid slag layer (about 6 15 mm) above the molten steel. The liquid slag layer can partly prevent the heat of molten steel from transferring; therefore, above the liquid slag layer, temperature drops, which forms a sintered layer (about $600 \sim 900^{\circ} \mathrm{C}$ ). Above the sintered layer, more heat is prevented; therefore, the TCF can keep its original pulverous characteristic to form a powder slag layer. The powder slag layer covers the molten steel surface evenly to prevent heat radiation and isolate oxygen.

In the continuous casting steelmaking process, due to crystallizer vibration and solidified shell movement, the liquid slag layer may slowly get into the gap between the shell and the copper wall of crystallizer. Therefore, along with the casting process, the liquid slag layer is constantly consumed by the molten steel and gets supplement from the sintered layer. Similarly, the sintered layer is constantly transformed into liquid slag layer and gets supplement from the powder slag layer. And the operator keeps an eye on the powder slag layer and adds new TCF into CC tundish as necessary. The thickness of TCF has a great effect on the continuous casting steelmaking process; if the TCF is too thin, the steel 


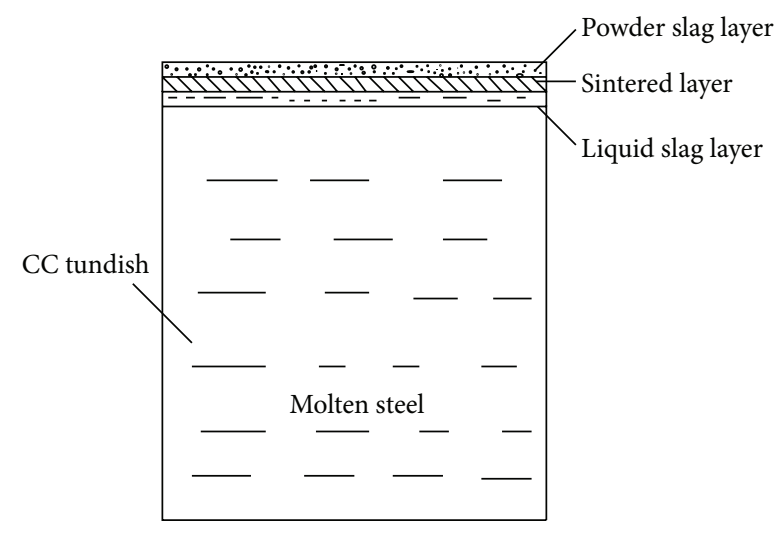

FIGURE 1: Schematic diagram of TCF three main components in the CC tundish, which are powder slag layer, sintered layer, and liquid slag layer.

will become carburized, unmelted slag patches will occur as surface defects, and worse of all the result can be a breakout because of too high friction between steel shell and mould. On the contrary, if the TCF is too thick, crystallized rim will emerge at the meniscus which will disturb the solidification process and cause surface defects on the steel. Therefore, TCF thickness is an essential parameter to guarantee the quality of strand surface and can provide important information for the operators to keep track of the status in the CC tundish.

Nowadays, in continuous casting steelmaking process, the most common used measurement methods for TCF thickness are single-wire measurement method and doublewire measurement method, because these two methods are cheap and easily operated. In single-wire measurement method, one iron wire is vertically inserted into the molten steel, and kept steady for 3 5 seconds. Then pull it out and measure the TCF thickness based on the length of color change and slag-adhering part (shown in Figure 2). In double-wire measurement method, one iron wire and one copper wire, which have the same length, are parallel and firmly tied together, then vertically inserted into the molten steel, and kept steady for 3 5 seconds. Melting point of the iron wire is higher than the temperature of liquid slag layer and lower than the temperature of the molten steel, therefore, the iron wire below the liquid slag layer is melted. Melting point of the copper wire is higher than the temperature of sintered layer and lower than the temperature of liquid slag layer; therefore, the copper wire below the sintered layer is melted. The whole thickness of TCF can be calculated based on the length of the color change and slag-adhering part on the iron wire. Compared with the singe-wire measurement method, the double-wire measurement method can specifically measure the thickness of the liquid slag layer using the length of the remaining iron wire minus the length of the remaining copper wire (shown in Figure 3). Although the single-wire measurement method and the double-wire measurement method are widely used in continuous casting steelmaking process, they both have insurmountable and severe shortcomings: (1) operators need to stand on the tundish to hold the wires, which means

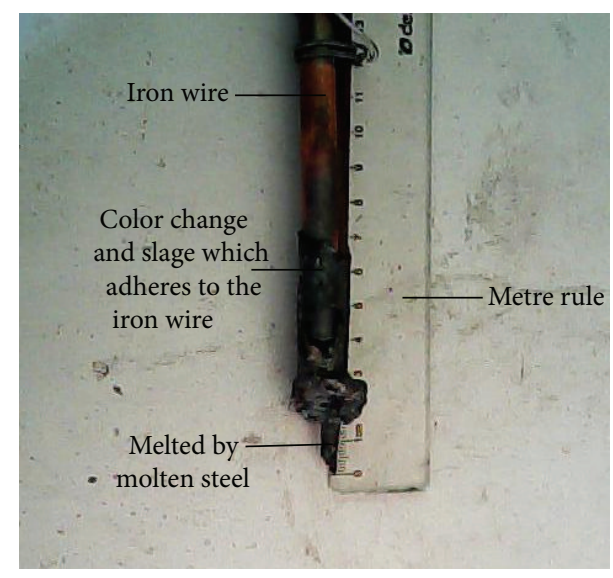

Figure 2: Single-wire measurement method of TCF thickness. TCF thickness can be measured by the length of color change and slagadhering part on the iron wire.

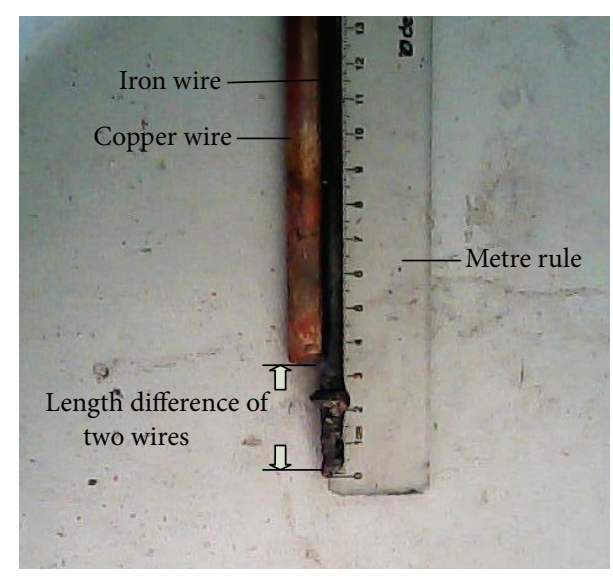

FIgURE 3: Double-wire measurement method of TCF thickness. The whole thickness of the TCF can be measured by the length of the color change and slag-adhering part on the iron wire. The thickness of the liquid slag layer can be measured by the length difference of two wires.

lethal danger to operators; (2) the detection results are easily influenced by the operators, such as hand trembling or not vertically holding the wires; (3) poor repeatability. All these shortcomings make these two TCF thickness measurement methods inaccurate and dangerous.

In this paper, a novel TCF thickness measurement method and instrumentation are proposed. We use a highdefinition industrial camera to collect the image information in the CC tundish, which is fastened to a customdesigned mechanical device. The thickness of TCF is calculated based on the computer vision algorithms, including image denoise method, monocular range measurement method, scale invariant feature transform (SIFT), and image gray gradient detection method. Our measurement method is noncontact measurement, full automatic working, good repetitiveness, and absolutely safe. 


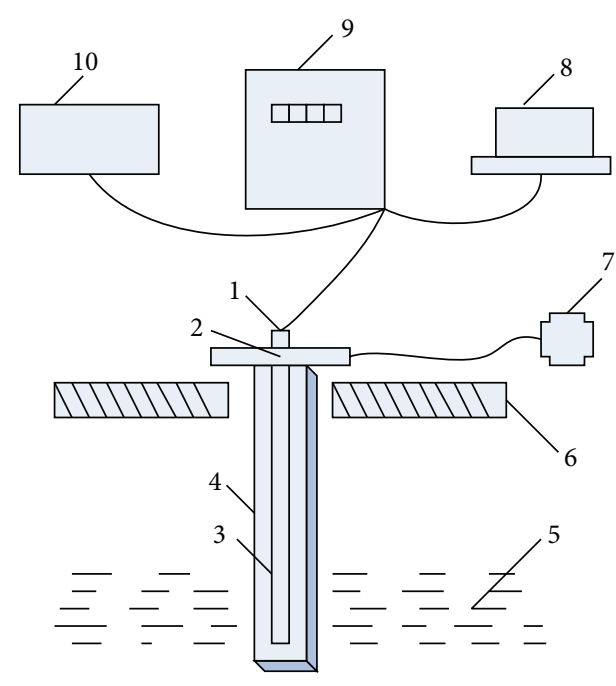

FIGURE 4: Schematic diagram of the continuous temperature measurement system based on the blackbody radiation theorem. (1) Temperature sensor, (2) optical lens, (3) internal tube, (4) external tube, (5) molten steel, (6) tundish, (7) bracket, (8) single-chip micyoco (SCM), (9) signal processor, and (10) display for temperature.

\section{Method}

The TCF thickness measurement method and instrumentation are an extension of a previous work from our group [521], which is continuous temperature measurement method and sensor for molten steel in CC tundish based on blackbody chamber theorem. We briefly recall it in order to make the following sections more clearly.

Theoretical principle of continuous temperature measurement method is blackbody radiation theorem:

$$
E_{b}=\left(\lambda, T_{L}\right)=\varepsilon^{T}(\lambda, T) \cdot E_{b}\left(T_{0}, \lambda\right) .
$$

$E_{b}$ represented the spectral radiosity of blackbody chamber, $\varepsilon^{T}$ represented the spectral emissivity of blackbody chamber, $T_{L}$ represented the brightness temperature of blackbody chamber, and $T$ represented the actual temperature of blackbody chamber.

Based on this theorem, we specifically made a measurement bar and used it as a temperature sensor, which was inserted into the molten steel to measure the temperature of molten steel. The measurement bar was the core component of the system, which was composed of external tube and internal tube. The external tube was heat resistant, shock resistant, and anti corrosion and had good heat conduction, which can offer protection for the internal tube. The internal tube was made of certain translucent medium, which had steady radiation characteristic and specular/diffusion reflection characteristic. Heat radiation in the measurement bar was transformed into electrical signal by a photoelectric transducer. And the electrical signal can be used to calculate the temperature of the molten steel based on the blackbody radiation theorem. The schematic diagram of the system was shown in Figure 4.

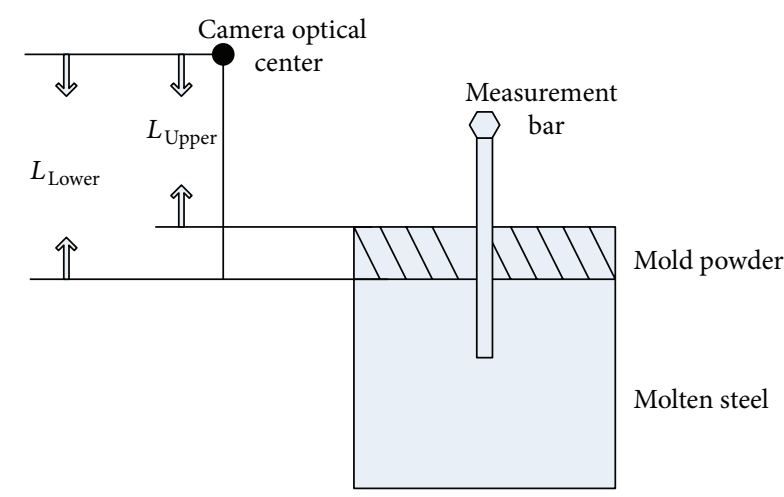

FIGURE 5: Schematic diagram of measurement bar, which is inserted into the molten steel.

More details about the continuous temperature method and sensor for molten steel in CC tundish can be referenced from [5-13].

2.1. Theory. The measurement bar is also the core component of TCF thickness measurement method and instrumentation. While the measurement bar is inserted into the molten steel, a high-definition industrial camera is used to collect the image information in the tundish. Based on computer vision algorithms, which are elaborated in the Sections 2.3 and 2.4, TCF thickness is calculated by

$$
L_{\text {powder }}=L_{\text {lower }}-L_{\text {upper }}
$$

where $L_{\text {lower }}$ represents the distance from TCF lower surface to optical center of the camera and $L_{\text {upper }}$ represents the distance from TCF upper surface to optical center of the camera (shown in Figure 5).

Molten steel and TCF have different thermal conductivities; therefore, these two different media have different temperatures, and there is obvious temperature gradient in the interface layer of these two media. While the measurement bar is inserted into the molten steel for long enough time (shown in Figure 5), the measurement bar can be in the state of thermal balance. And then the measurement bar is pulled up; the temperature information of molten steel and TCF can be reflected by the luminance of the measurement bar (shown in Figure 6). In Figure 6(a), the brighter zone indicates that this part of the measurement bar is in the molten steel before being pulled up, and the darker zone indicates that this part of the measurement bar is in the TCF before being pulled up. The arrow indicates the peak value of image gradient between the brighter zone and the darker zone, which is also the interface layer between the molten steel and the TCF. In Figure 6(b), it can be seen that the temperature on the measurement bar has an intense change, which causes the peak value of the temperature gradient indicated by the arrow. These two arrows in both Figures 6(a) and 6(b) actually point to the same location of the measurement bar, which is the lower surface of the TCF. Therefore, the distance from TCF lower surface to optical center of the camera can be calculated by gray gradient detection in the image, which is elaborated in Section 2.4. 


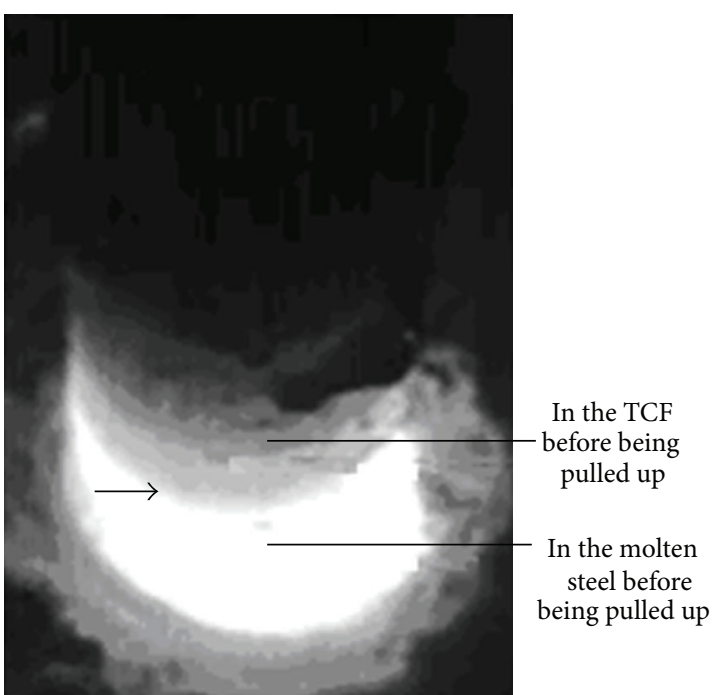

(a)

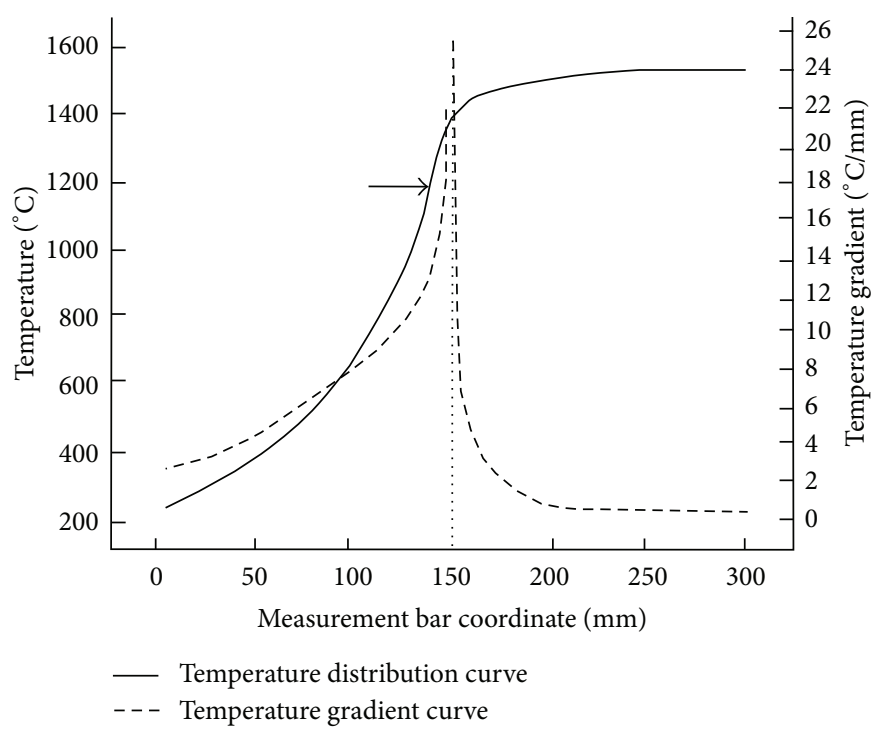

(b)

FIGURE 6: The surface condition of the measurement bar, when the measurement bar is pulled up from the molten steel. (a) Luminance information on the measurement bar, on which obvious image gray scale difference can be seen. (b) Schematic diagram of temperature distribution and gradient curve on the measurement bar. Horizontal ordinate represents coordinates of the measurement bar, left vertical ordinate represents the temperature of the measurement bar, and the right vertical ordinate represents the temperature gradient of the measurement bar.

2.2. Instrumentation. As mentioned before, the measurement bar is inserted into the molten steel; therefore, a specialized mechanical device is required to hold the measurement bar, and the camera is also fixed on the mechanical device (shown in Figure 7). The mechanical device can ascend and descend under the control of frequency conversion motor, and the measurement bar can be lifted and lowered with the movement of the mechanical device. The camera is fixed and well-secured on the crossbeam of the mechanical device, and in case of overheating, the camera is cooled down by cool air through ventilating pipe. With the help of this mechanical device, the height of the crossbeam, the temperature of the measurement bar, and images collected by the camera are transferred to the computer and the programmable logic controller (PLC, Siemens S7-200). We can use all these information to make judgments and calculate TCF thickness. The main functions of the computer are imaging processing and displaying the calculation result of TCF thickness. The main functions of the PLC are controlling the movement of the mechanical device and making it accurate and steady. The schematic diagram of the whole instrumentation system is shown in Figure 8.

2.3. TCF Upper Surface Distance Measurement. The distance from TCF upper surface to the optical center of camera is calculated based on the principle of monocular distance measurement $[22,23]$. Two images $I_{1}, I_{2}$ can be obtained while the camera is moved from position $P_{1}$ to position $P_{2}$. In

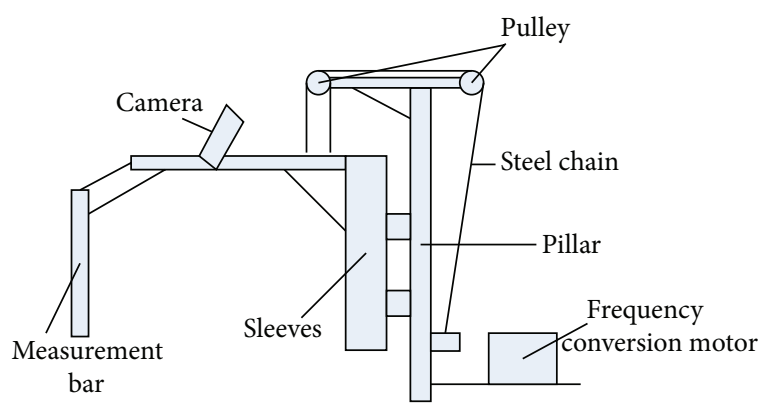

FIgURE 7: Schematic diagram of mechanical device, which holds the camera and measurement bar.

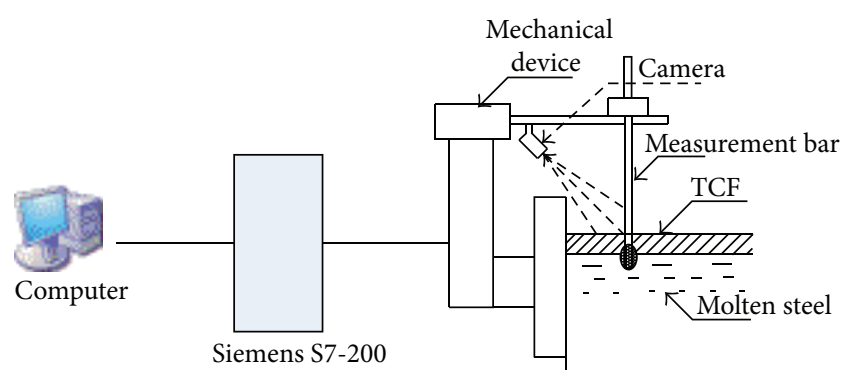

FIGURE 8: Schematic diagram of the whole instrumentation system, including computer, Siemens S7-200, mechanical device, camera, and measurement bar. 


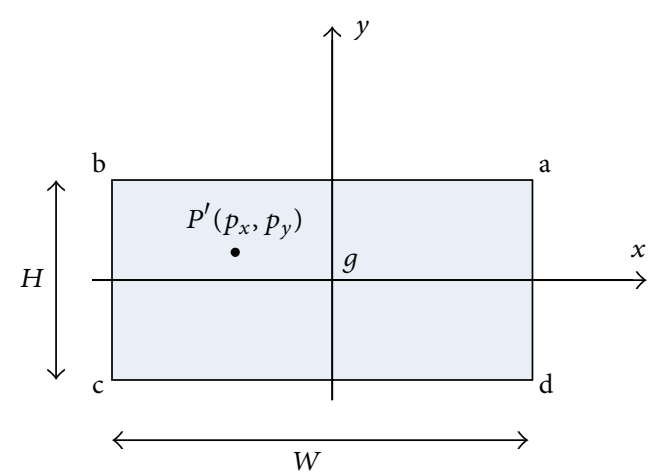

FIGURE 9: Schematic diagram of image coordinate system. $g$ is the base point, which is in the center of the image, $P^{\prime}$ represents one pixel in the image with coordinate $\left(p_{x}, p_{y}\right), x-g-y$ represents the rectangular coordinate system, $W$ represents the width of the image, and $H$ represents the height of the image.

these two images, the same objects have different coordinates due to the camera movement. According to the coordinate differences and the movement distance from $P_{1}$ to $P_{2}$, the distance from the objects to the optical center of camera can be calculated. And there are two key steps in the calculation: (1) the transformation from image coordinates to the world coordinates; (2) matching the corresponding pixels of the same objects in two images $I_{1}$ and $I_{2}$.

2.3.1. Transformation from the Image Coordinates to the World Coordinates. Suppose that the image coordinates are defined as $\left(p_{x}, p_{y}\right)$, and the world coordinates are defined as $\left(P_{x}, P_{y}, P_{z}\right)$. We can see that the image coordinates are two-dimensional and the world coordinates are threedimensional; therefore, one of the world coordinates should be set as constant. The base point of the image coordinate system is defined as the center of the image (shown in Figure 9). The base point of the world coordinate system is defined as the intersection point of TCF upper surface and the optical axis originated from the camera's optical center (shown in Figure 10); therefore, $P_{z} \equiv 0$. The transformation from image coordinates $\left(p_{x}, p_{y}\right)$ to the world coordinates $\left(P_{x}, P_{y}, P_{z}\right)$ is defined as formula (3), and the details of proof can be obtained in appendix.

In Figure 10, plane $A B U$ represents TCF upper surface, $A B C D$ represents the camera's field of view, point $O$ represents the camera's optical center, line $O G$ represents the camera's optical axis, point $G$ represents the intersection point of optical axis and plane $A B U$, point $G$ is also the base point of the world coordinate system, point $I$ represents the projection point of optical center $O$ on the plane $A B U$, and the distance from point $O$ to point $I$ is $h . X-G-Y$ represents the rectangular coordinate system. $2 \alpha_{0}$ represents the camera's vertical field angle, $2 \beta_{0}$ represents the camera's horizontal field angle, and $\gamma_{0}$ represents the camera's pitch angle. Namely, $\angle E O F=2 \alpha_{0}$, line $O G$ equally divides $\angle E O F ; \angle K O J=2 \beta_{0}$, line $O G$ equally divides $\angle K O J, \angle G O I=\gamma_{0}$. Point $P$ is any point on the TCF upper surface, and its world coordinate is $\left(P_{x}, P_{y}\right)$ in the rectangular coordinate system $X-G-Y$. From point $P$, draw

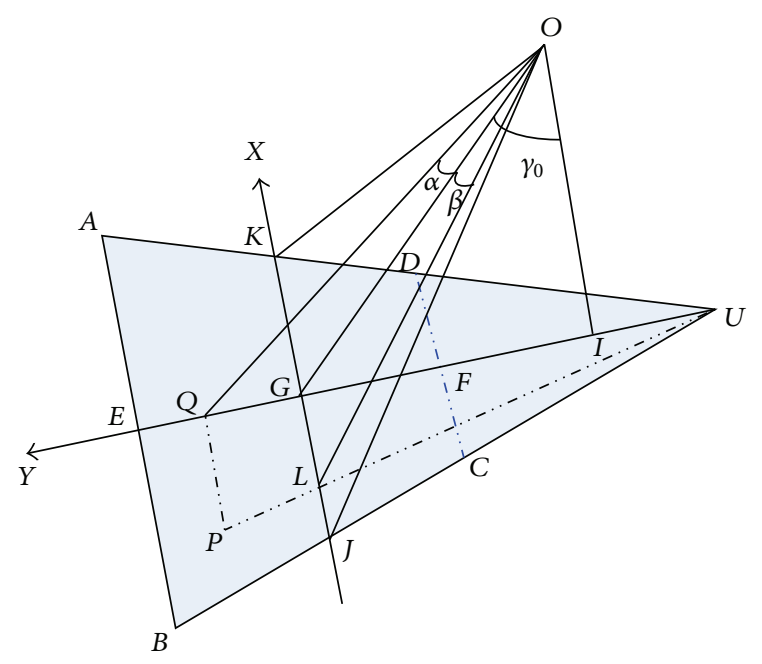

FIgURE 10: Schematic diagram of world coordinate system.

perpendicular line on the axis $G Y$, and the perpendicular foot is point $Q$; therefore, $P_{y}=G Q$. Connect point $P$ and point $U$, and line $P U$ intersects axis $G X$ at point $L$; therefore, $P_{x}=G L$. Connect point $L$ and optical center $O$, and the intersection angle of line $O L$ and optical axis is $\beta$. Connect point $Q$ and optical center $O$, and the intersection angle of line $O Q$ and optical axis is $\alpha$ :

$$
\begin{gathered}
\alpha=\operatorname{arctg} \frac{2 p_{y} \times \operatorname{tg} \alpha_{0}}{H}, \\
\beta=\operatorname{arctg} \frac{2 p_{x} \times \operatorname{tg} \beta_{0}}{W}, \\
P_{x}=\frac{h}{\cos \gamma_{0}} \times \operatorname{tg} \beta \\
\times\left(1+\frac{\left(\operatorname{tg}\left(\gamma_{0}+\alpha\right)-\operatorname{tg} \gamma_{0}\right) \times\left(\cos \left(\gamma_{0}-\alpha_{0}\right)-\cos \gamma_{0}\right)}{\left(\operatorname{tg} \gamma_{0}-\operatorname{tg}\left(\gamma_{0}-\alpha_{0}\right)\right) \times \cos \left(\gamma_{0}-\alpha_{0}\right)}\right), \\
P_{y}=h\left(\operatorname{tg}\left(\gamma_{0}+\alpha\right)-\operatorname{tg} \gamma_{0}\right), \\
P_{z}=0 .
\end{gathered}
$$

$H$ represents the height of the image, $W$ represents the width of the image, $h$ represents the vertical distance from camera's optical center to the TCF upper surface, $2 \alpha_{0}$ represents the camera's vertical field angle, $2 \beta_{0}$ represents the camera's horizontal field angle, and $\gamma_{0}$ represents the camera's pitch angle.

Based on formula (3), the world coordinates of any point on the TCF upper surface can be calculated, and the only unknown parameter is $h$, which is the distance from the TCF upper surface to the camera's optical center. By moving the camera vertically from $h_{1}$ to $h_{2}\left(h_{2}>h_{1}\right)$, although $h_{1}$ and $h_{2}$ are unknown, $\Delta h=h_{1}-h_{2}$ can be obtained (shown in Figure 11). Suppose that the same object on the TCF upper surface has one world coordinate $P_{1}(a, b)$ before movement 


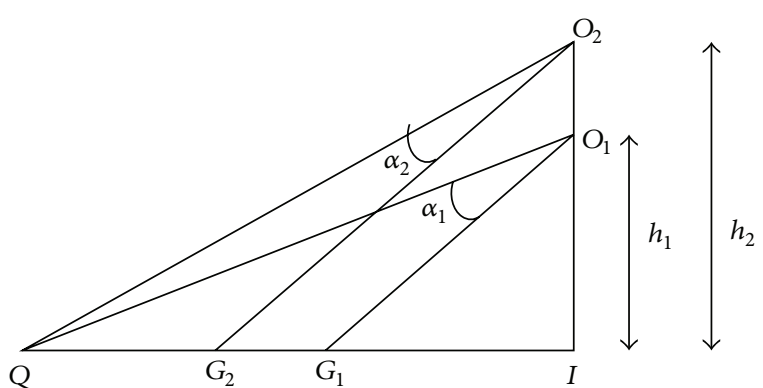

FIGURE 11: Schematic diagram of moving camera from $h_{1}$ to $h_{2}$. While the camera is moved from $h_{1}$ to $h_{2}$, then the camera's optical center is moved from $\mathrm{O}_{1}$ to $\mathrm{O}_{2}$ after movement: therefore, the base point of world rectangular coordinate system is also moved from $G_{1}$ to $G_{2}$.

and another world coordinate $P_{2}(c, d)$ after movement. While the camera is moved from $h_{1}$ to $h_{2}$, then the camera's optical center is moved from $\mathrm{O}_{1}$ to $\mathrm{O}_{2}$ after movement; therefore, the base point of world rectangular coordinate system is also moved from $G_{1}$ to $G_{2}$. Because the movement of camera is vertical, two world rectangular coordinate systems have the same $y$-axis and different $x$-axis; therefore, $P_{1}$ and $P_{2}$ have the same horizontal coordinates in the world coordinate system, namely, $a=c$. Therefore, the distance from TCF upper surface to camera optical center can be calculated by formula (4):

$$
\begin{aligned}
& \frac{h_{1}}{\cos \gamma_{0}} \times \operatorname{tg} \beta_{1} \\
& \times\left(1+\frac{\left(\operatorname{tg}\left(\gamma_{0}+\alpha_{1}\right)-\operatorname{tg} \gamma_{0}\right) \times\left(\cos \left(\gamma_{0}-\alpha_{0}\right)-\cos \gamma_{0}\right)}{\left(\operatorname{tg} \gamma_{0}-\operatorname{tg}\left(\gamma_{0}-\alpha_{0}\right)\right) \times \cos \left(\gamma_{0}-\alpha_{0}\right)}\right) \\
& =\frac{h_{2}}{\cos \gamma_{0}} \times \operatorname{tg} \beta_{2} \\
& \times\left(1+\frac{\left(\operatorname{tg}\left(\gamma_{0}+\alpha_{2}\right)-\operatorname{tg} \gamma_{0}\right) \times\left(\cos \left(\gamma_{0}-\alpha_{0}\right)-\cos \gamma_{0}\right)}{\left(\operatorname{tg} \gamma_{0}-\operatorname{tg}\left(\gamma_{0}-\alpha_{0}\right)\right) \times \cos \left(\gamma_{0}-\alpha_{0}\right)}\right) \\
& h_{2}-h_{1}=\Delta h, \\
& \alpha_{1}=\operatorname{arctg} \frac{2 p_{y 1} \times \operatorname{tg} \alpha_{0}}{H} \\
& \beta_{1}=\operatorname{arctg} \frac{2 p_{x 1} \times \operatorname{tg} \beta_{0}}{W} \\
& \alpha_{2}=\operatorname{arctg} \frac{2 p_{y_{2}} \times \operatorname{tg} \alpha_{0}}{H} \\
& \beta_{2}=\operatorname{arctg} \frac{2 p_{x 2} \times \operatorname{tg} \beta_{0}}{W} .
\end{aligned}
$$

2.3.2. Matching the Corresponding Pixels of the Same Objects in Two Images. SIFT based image registration method is used to match the corresponding pixels of the same objects in two images. SIFT was published by Lowe in 1999 [24] and improved in 2004 [25], which was used to detect and describe local image features. SIFT is an excellent feature descriptor, because it is invariant to uniform scaling, orientation, and partially invariant to affine distortion and illumination changes. SIFT's application includes object recognition, robotic mapping and navigation, image stitching, 3D modeling, gesture recognition, video tracking, individual identification of wildlife, and match moving.

Scale space is a formal theory for handling image structures at different scales from physical and biological vision, by representing an image as a one-parameter family of smoothed images. The main type of scale-space is the linear (Gaussian) scale-space, which can be defined by

$$
L(x, y, \sigma)=G(x, y, \sigma) * I(x, y) .
$$

$I(x, y)$ represents one image, $*$ represents convolution, and $G(x, y, \sigma)$ represents Gaussian filter function:

$$
G(x, y, \sigma)=\frac{\left(1 / 2 \pi \sigma^{2}\right) e^{-\left(x^{2}+y^{2}\right)}}{2 \sigma^{2}} .
$$

$(x, y)$ represents image coordinates, and $\sigma$ represents scale level. Therefore, difference of Gaussian (DoG) scale space can be defined as

$$
\begin{aligned}
D(x, y, \sigma) & =(G(x, y, k \sigma)-G(x, y, \sigma)) * I(x, y) \\
& =L(x, y, k \sigma)-L(x, y, \sigma) .
\end{aligned}
$$

Once DoG images have been obtained, keypoints are identified as local minima/maxima of the DoG images across scales. This is done by comparing each pixel in the DoG images to its eight neighbors at the same scale and nine corresponding neighboring pixels in each of the neighboring scales. If the pixel value is the maximum or minimum among all compared pixels, it is selected as a candidate keypoint.

Scale-space extreme detection produces too many keypoint candidates, some of which are unstable. The next step in the algorithm is to perform a detailed fit to the nearby data for accurate location, scale, and ratio of principal curvatures. This information allows points to be rejected that have low contrast (and are therefore sensitive to noise) or are poorly localized along an edge.

The interpolation of keypoints is done using the quadratic Taylor expansion of the DoG scale-space function:

$$
D(X)=D+\frac{\partial D^{T}}{\partial X} X+\frac{1}{2} X^{T} \frac{\partial^{2} D}{\partial X^{2}} X
$$

Then, the location of the extreme $\widehat{X}$ is determined by taking the derivative of this function with respect to $X$ and setting it to zero:

$$
\begin{gathered}
\widehat{X}=-\frac{\partial^{2} D^{-1}}{\partial X^{2}} \frac{\partial D}{\partial X}, \\
D(\widehat{X})=D+\frac{1}{2} \frac{\partial D^{T}}{\partial X} \widehat{X} .
\end{gathered}
$$


The DoG function will have strong responses along edges, even if the candidate keypoint is not robust to small amounts of noise. Therefore, in order to increase stability, the Hessian matrix is used to eliminate the keypoints that have poorly determined locations but have high edge responses:

$$
\begin{gathered}
H=\left[\begin{array}{ll}
D_{x x} & D_{x y} \\
D_{x y} & D_{y y}
\end{array}\right], \\
\operatorname{Tr}(H)=D_{x x}+D_{y y}=\alpha+\beta, \\
\operatorname{Det}(H)=D_{x x} D_{y y}-\left(D_{x y}\right)^{2}=\alpha \beta .
\end{gathered}
$$

$\alpha$ represents bigger eigenvalue, and $\beta$ represents smaller eigenvalue. Suppose that $\alpha=r \beta$. We can get

$$
R=\frac{\operatorname{Tr}(H)^{2}}{\operatorname{Det}(H)}=\frac{(\alpha+\beta)^{2}}{\alpha \beta}=\frac{(r \beta+\beta)^{2}}{r \beta^{2}}=\frac{(r+1)^{2}}{r} .
$$

It follows that, for some threshold eigenvalue ratio $r_{\text {th }}$, if $R$ for a candidate keypoint is larger than $\left(r_{\text {th }}+1\right)^{2} / r_{\text {th }}$, that keypoint is poorly localized and hence rejected.

Each keypoint is assigned one or more orientations based on local image gradient directions. This is the key step in achieving invariance to rotation as the keypoint descriptor can be represented relative to this orientation and therefore achieve invariance to image rotation:

$$
\begin{gathered}
m(x, y)=\sqrt{(L(x+1, y)-L(x-1, y))^{2}+(L(x, y+1)-L(x, y-1))^{2}} \\
\theta(x, y)=\tan ^{-1}\left(\frac{L(x, y+1)-L(x, y-1)}{L(x+1, y)-L(x-1, y)}\right)
\end{gathered}
$$

$m(x, y)$ represents the gradient magnitude, and $\theta(x, y)$ represents the orientation.

A set of orientation histograms are created on $4 \times 4$ pixel neighborhoods with 8 bins each. These histograms are computed from magnitude and orientation values of samples in a $16 \times 16$ region around the keypoint such that each histogram contains samples from a $4 \times 4$ subregion of the original neighborhood region. The magnitudes are further weighted by a Gaussian function with $\sigma$ equal to one half the width of the descriptor window. The descriptor then becomes a vector of all the values of these histograms. Since there are $4 \times 4=16$ histograms each with 8 bins, the vector has 128 elements. This vector is then normalized to unit length in order to enhance invariance to affine changes in illumination.

The SIFT feature descriptors extracted from two images $I_{1}, I_{2}$ while the camera is moved from position $P_{1}$ to position $P_{2}$ are shown in Figure 12.

2.4. TCF Lower Surface Distance Measurement. While the measurement bar is pulled out, due to the temperature difference, there is temperature gradient on the measurement bar. And the temperature gradient is reflected as gray gradient in the image (shown in Figure 6). Therefore, the distance from TCF lower surface to the camera optical center is calculated based on gray gradient detection in the image.
The measurement bar and the camera are both fixed in the mechanical device, so they are in the relatively static state. Therefore, in the image, pixels in the middle line of measurement bar have constant distance to the camera optical center. Suppose that $\left(L_{x}, L_{y}\right)$ represents pixel coordinate and $d$ represents the pixel's distance to camera optical center. The function $\left\{f: L_{y} \rightarrow d\right\}$ can be obtained (shown in Figure 13).

There is a pitch angle between camera optical axis and the middle line of the measurement bar $\left(21.5^{\circ}\right.$ in this paper); therefore, pixels in the middle line of the measurement bar have different spatial resolutions ( $\mathrm{mm} /$ pixel), and the bigger the vertical coordinate is, the higher the spatial resolution is. Suppose that $\left(L_{x}, L_{y}\right)$ represents pixel coordinate, and $s r$ represents the pixel's spatial resolution, the function $\{g$ : $\left.L_{y} \rightarrow s r\right\}$ can be obtained (shown in Figure 14).

In the continuous casting steelmaking process, the range of the TCF thickness is $5 \mathrm{~mm} \sim 50 \mathrm{~mm}$. Given the prior knowledge, the functions $f$ and $g$, and the distance from the TCF upper surface to the optical center, the image region of interest (ROI) on the measurement bar can be obtained. And in the ROI, the Gaussian-Laplace operator is used to detect the gray gradient (shown in Figure 15). While the gray gradient caused by TCF lower surface is detected, distance from TCF lower surface to camera optical center can be obtained by using function $f$.

2.5. Implementation. The steps below outline the procedure for measuring the thickness of TCF, and the Steps (2)-(7) are circularly implemented every 30 minutes.

(1) Initialization. Prepare the mechanical device, move it to the specified location, check the status of the movement bar and the camera, and ensure that they are steadily fixed. Then control the mechanical device to insert the movement bar in the molten steel.

(2) Thermal Balance. Keep the movement bar in the molten steel long enough to make it in the thermal balance (30 minutes in this paper). And save the current position as $p_{1}$ and current image as $I_{1}$.

(3) Pulling out the Measurement Bar. Control the mechanical device to pull out the measurement bar, and save the current position as $p_{2}$ and current image as $I_{2}$.

(4) Distance Calculation from TCF Upper Surface to Camera Optical Center. Use formula (4) to calculate the distance from TCF upper surface to camera optical center, and save it as $L_{\text {upper}}$.

(5) Distance Calculation from TCF Lower Surface to Camera Optical Center. Use the Gaussian-Laplace operator to obtain the image gray gradient caused by TCF lower surface, and use the function $\left\{f: L_{y} \rightarrow d\right\}$ to calculate the distance from TCF lower surface to camera optical center, and save it as $L_{\text {lower }}$.

(6) TCF Thickness Calculation. Use formula (2) to calculate the TCF thickness. 


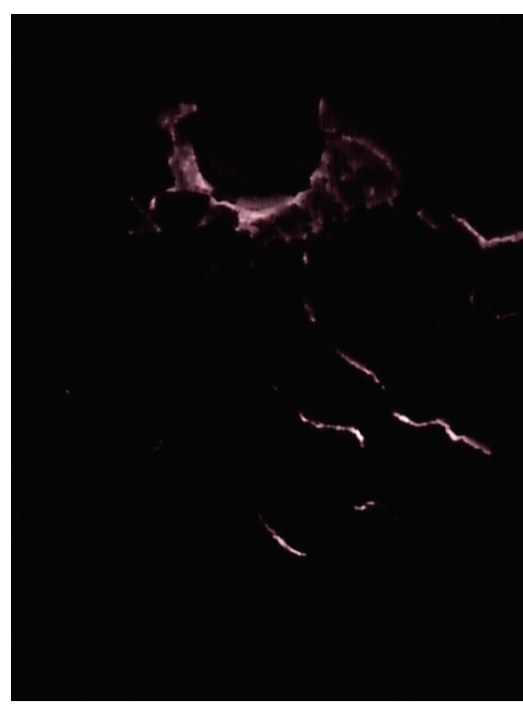

(a)

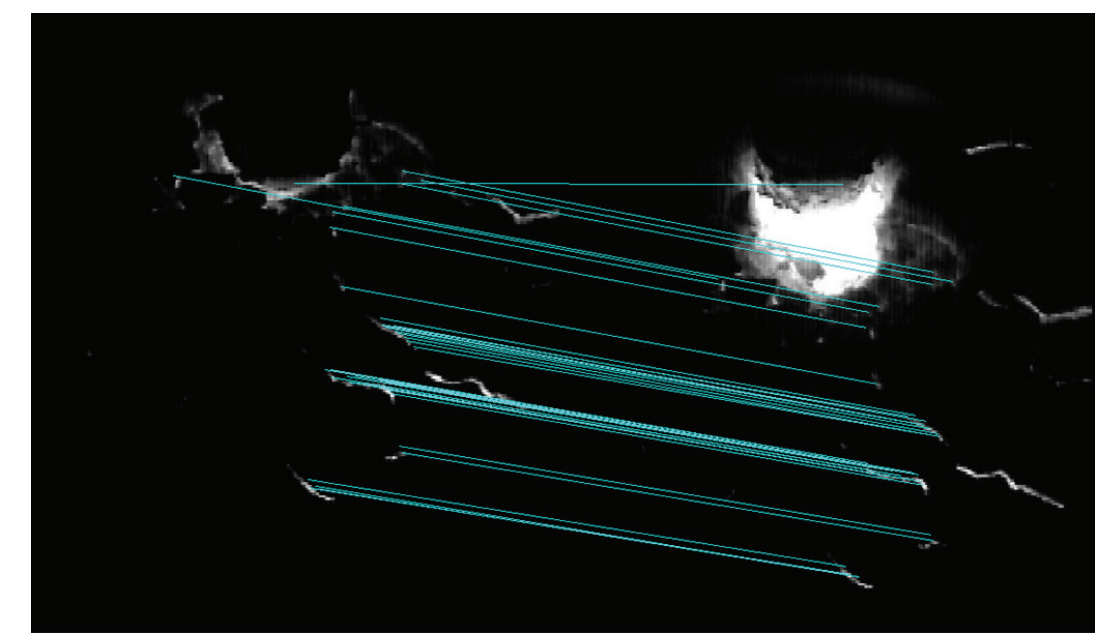

(c)

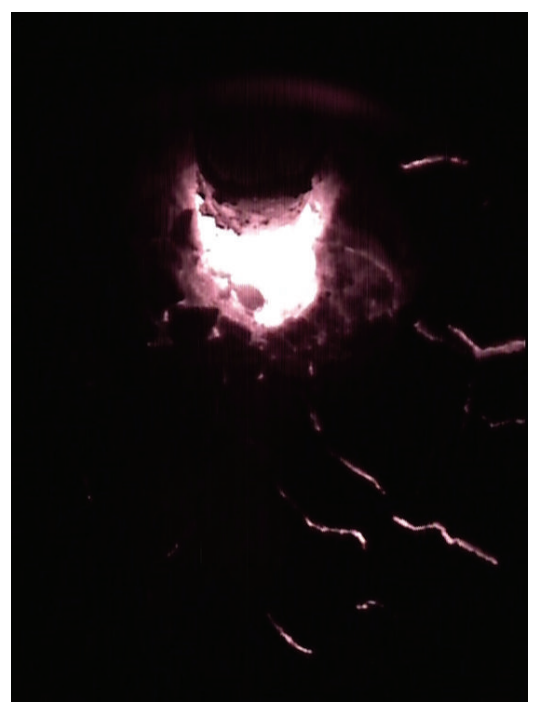

(b)

FIGURE 12: Schematic diagram of matching the corresponding pixels in two images based on SIFT descriptors, (a) image $I_{1}$ in position $P_{1}$, (b) image $I_{2}$ in position $P_{2}$ after the measurement bar is pulled out, and (c) matching the corresponding pixels in two images based on SIFT descriptors.

(7) End Measurement. Control the mechanical device to insert the measurement bar in the molten steel, and then implement Step (2).

\section{Experiments and Results}

The TCF thickness measurement instrumentation has alread$\mathrm{y}$ been installed and applied in four Chinese steel plants, which are Nanjing Steel Plant located in Jiangsu province since 2010, Daye Steel Plant located in Hubei province since 2011, Hanzhou Steel Plant located in Zhejiang province since 2011, and Sanming Steel Plant located in Fujian province since 2012. The instrumentation works well in these four worksites, and Figure 16 shows the working condition at scene.
3.1. Experiment of TCF Upper Surface Distance Measurement. We did this experiment to verify the correctness and accuracy of the method discussed in Section 2.3. The experiment steps are as follows

(1) We localized the mechanical device in position $P_{1}$ and manually measured the distance from the camera to the TCF upper surface (700 $\mathrm{mm}$ in this experiment) and then saved the image in this position as $I_{1}$.

(2) We lifted the mechanical device in position $P_{2}\left(P_{2}-\right.$ $P_{1}=50 \mathrm{~mm}$ in this experiment) and then saved the image in this position as $I_{2}$.

(3) We did image registration for images $I_{1}$ and $I_{2}$ based on SIFT and matched the corresponding pixels in 


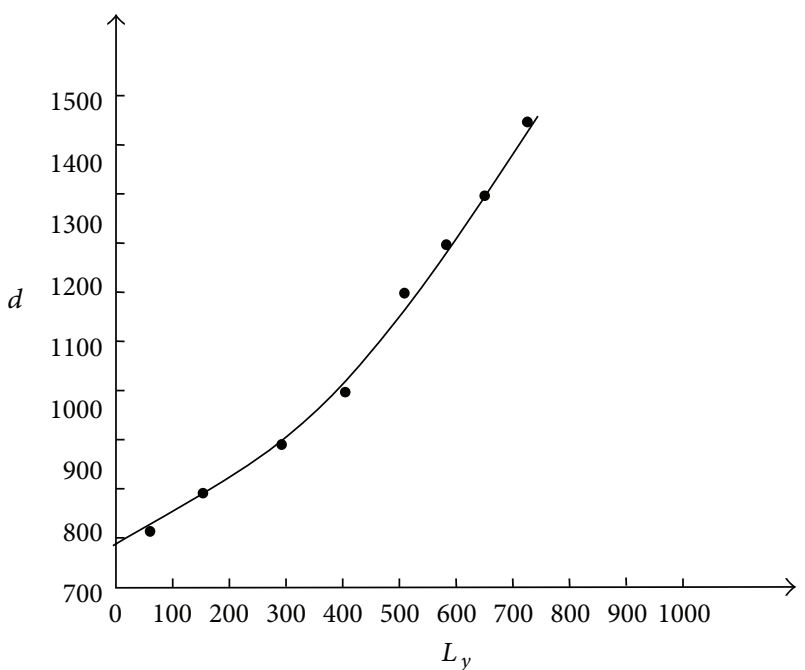

FIGURE 13: Schematic diagram of the relationship between pixels' vertical coordinates in the middle line of the measurement bar and its distance to the camera optical center. - represents the sampling points.

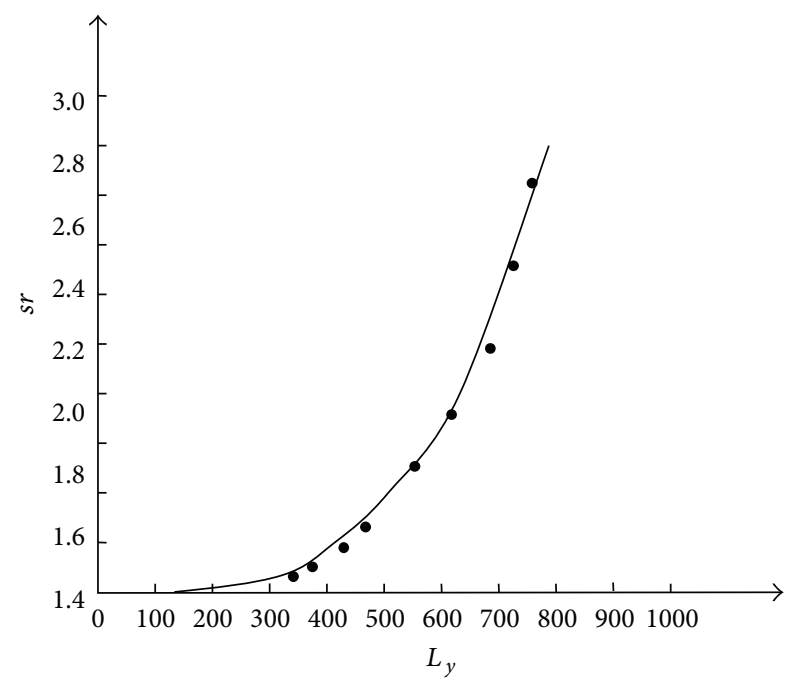

FIGURE 14: Schematic diagram of the relationship between pixels' vertical coordinates in the middle line of the measurement bar and its spatial resolution. $\bullet$ represents the sampling points.

these two images (226 pixels were matched in this experiment).

(4) We set the parameters in formula (4). $\Delta h$ represents lifted distance from $P_{1}$ to $P_{2}(50 \mathrm{~mm}$ in this experiment), $2 \alpha_{0}$ represents vertical angle of view $\left(42.6^{\circ}\right.$ in this experiment), $2 \beta_{0}$ represents horizontal angle of view $\left(50^{\circ}\right.$ in this experiment), $\gamma_{0}$ represents angle of pitch $\left(21.5^{\circ}\right.$ in this experiment), and $\left(p_{x_{1}}, p_{y_{1}}\right)$ and $\left(p_{x 2}, p_{y_{2}}\right)$ represent the coordinates of corresponding pixels in images $I_{1}$ and $I_{2}$. Table 1 showed the horizontal and vertical angles of view of several kinds lens, which had different sizes and focuses.
TABLE 1: Horizontal and vertical angles of view of several kinds lens, which have different sizes and focuses.

\begin{tabular}{lcccc}
\hline $\begin{array}{l}\text { Focus } \\
(\mathrm{mm})\end{array}$ & $\begin{array}{c}\text { Horizontal } \\
\text { angle of } \\
\text { view for } \\
1 / 3 \text { inch }\end{array}$ & $\begin{array}{c}\text { Vertical } \\
\text { angle of } \\
\text { view for } \\
1 / 3 \text { inch }\end{array}$ & $\begin{array}{c}\text { Horizontal } \\
\text { angle of } \\
\text { view for } \\
1 / 4 \text { inch }\end{array}$ & $\begin{array}{c}\text { Vertical } \\
\text { angle of } \\
\text { view for } \\
1 / 4 \text { inch }\end{array}$ \\
\hline $2.5 \mathrm{~mm}$ & $96.4^{\circ}$ & $86.2^{\circ}$ & $81.9^{\circ}$ & $72.9^{\circ}$ \\
$2.8 \mathrm{~mm}$ & $89.9^{\circ}$ & $79.8^{\circ}$ & $75.6^{\circ}$ & $66.8^{\circ}$ \\
$3.6 \mathrm{~mm}$ & $75.7^{\circ}$ & $66^{\circ}$ & $62.2^{\circ}$ & $54.3^{\circ}$ \\
$4 \mathrm{~mm}$ & $69.9^{\circ}$ & $60.7^{\circ}$ & $57^{\circ}$ & $49.5^{\circ}$ \\
$6 \mathrm{~mm}$ & $50^{\circ}$ & $42.6^{\circ}$ & $39.8^{\circ}$ & $34.2^{\circ}$ \\
$8 \mathrm{~mm}$ & $38.5^{\circ}$ & $32.6^{\circ}$ & $30.4^{\circ}$ & $26^{\circ}$ \\
$12 \mathrm{~mm}$ & $26.2^{\circ}$ & $22.1^{\circ}$ & $20.5^{\circ}$ & $17.5^{\circ}$ \\
$16 \mathrm{~mm}$ & $19.8^{\circ}$ & $16.6^{\circ}$ & $15.4^{\circ}$ & $13.2^{\circ}$ \\
$30 \mathrm{~mm}$ & $10.6^{\circ}$ & $8.9^{\circ}$ & $8.3^{\circ}$ & $77^{\circ}$ \\
$60 \mathrm{~mm}$ & $5.3^{\circ}$ & $4.5^{\circ}$ & $4.1^{\circ}$ & $3.5^{\circ}$ \\
$100 \mathrm{~mm}$ & $3.2^{\circ}$ & $2.7^{\circ}$ & $2.5^{\circ}$ & $2.1^{\circ}$ \\
$200 \mathrm{~mm}$ & $1.6^{\circ}$ & $1.3^{\circ}$ & $1.2^{\circ}$ & $1.1^{\circ}$ \\
\hline
\end{tabular}

(5) We used formula (4) to calculate the distance from camera to TCF upper surface and compared the calculated results with the actual distance $(700 \mathrm{~mm}$ in this experiment). The calculation and comparison details were shown in Table 2.

From the comparison shown in Table 2, average deviation is $1.2 \mathrm{~mm}$, and the biggest deviation is $2.2 \mathrm{~mm}$; therefore, we can conclude that the method in Section 2.3 based on monocular vision and image registration can accurately calculate the distance from the camera to TCF upper surface.

3.2. Comparison between Our Method and Single/Double Wire Methods on TCF Thickness Measurement. In this experiment, the results of our method were compared with the traditional methods, which are single-wire measurement method and double-wire measurement method. Although single/double wire measurement methods have several disadvantages, such as easily affected by the operator, dangerous to the operator, and poor repeatability, they are still the most common used and the most accredited methods in continuous casting steelmaking process. Therefore, we took these two methods as the golden standard to verify the correctness and accuracy of our method.

To improve the accuracy of the single/double wire measurement methods and reduce the human interference from the operators as far as possible, two operators were asked to join the experiment and strictly obey the following rules: (1) standing on the secure spot and staying alert; (2) vertically inserting the wires into the molten steel; (3) keeping the hand steady while the wires are in the molten steel; (4) keeping the wires in the molten steel for five seconds; (5) pulling the wires out of the molten steel as quickly as possible while the time is up. One operator measured the TCF thickness using one-wire measurement method, and the other one measured the TCF thickness using two-wire measurement method. While our instrumentation measured the TCF thickness, 


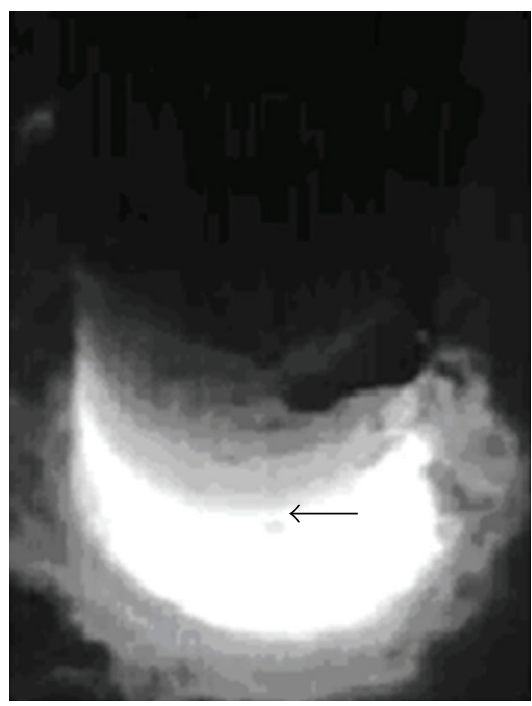

(a)

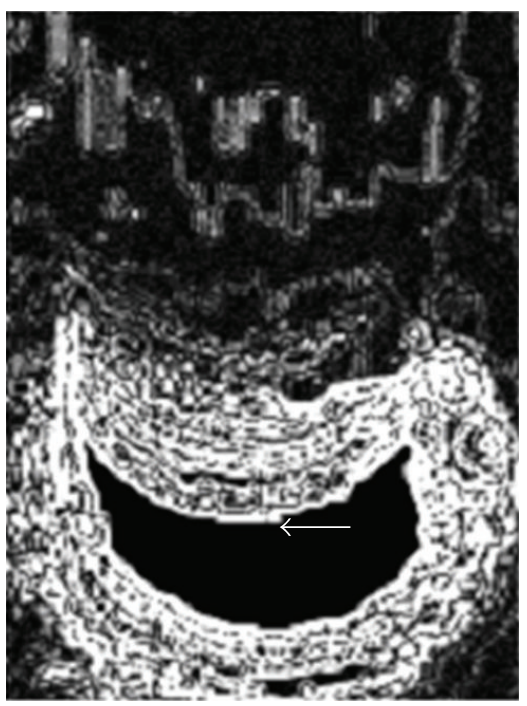

(b)

FIGURE 15: (a) Original image, (b) result of gray gradient detection. Arrows represent the gray gradient caused by TCF lower surface.

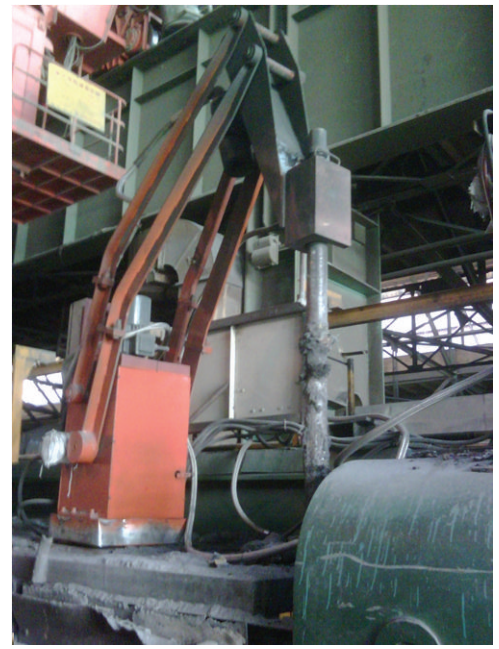

(a)

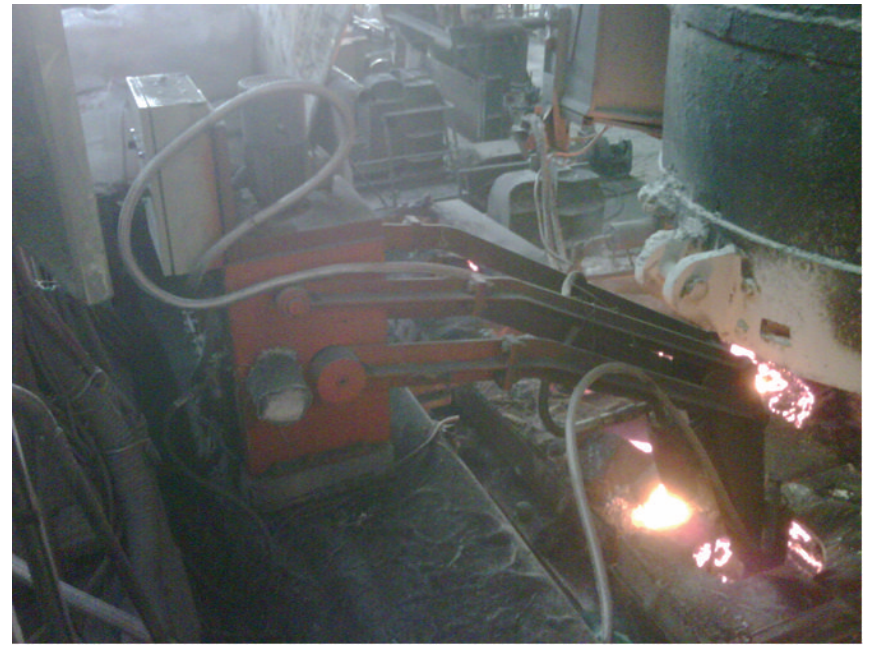

(b)

FIGURE 16: Working condition of our instrumentation at scene, (a) in the idle condition, (b) in the working condition.

both operators simultaneously measured the TCF thickness using single/double wire measurement methods. In this way, we can obtain three groups of experimental data at the same time to make the comparison, one from our method, two from single/double wire measurement methods.

The main ingredient of the TCF was shown in Table 3. The operator was asked to add one bag of TCF through each tundish hole every two hours, and the weight of one bag of TCF was about $10 \mathrm{~kg}$.

We did this experiment in two steel plants, respectively, which are Sanming Steel Plant and Nanjing Steel Plant. The error range that can be accepted by the steel plants is $\pm 5 \mathrm{~mm}$. Because the variation of TCF thickness is slow, we measured the TCF thickness every 30 minutes using both our method and the traditional single/double wire measurement methods. The experiments took ten hours in Sanming Steel Plant and nine hours in Nanjing Steel Plant. The measurement results and comparison between our method and the traditional single/double wire measurement methods were shown in Table 4 (Sanming Steel Plant) and Table 5 (Nanjing Steel Plant), and the comparisons were also shown in Figures 17 and 18.

It is shown in Table 4 that in the experiment of Sanming Steel Plant, the biggest deviation of our method from singlewire measurement method is $5.7 \mathrm{~mm}$ and the mean deviation of our method from single-wire measurement method is $3.0 \mathrm{~mm}$, and in the experiment of Sanming Steel Plant, the biggest deviation of our method from double-wire measurement method is $6.3 \mathrm{~mm}$ and the mean deviation of our method from double-wire measurement method is $2.8 \mathrm{~mm}$. 
TABLE 2: Calculated distance from TCF upper surface to camera optical center, and the comparison between calculated distance and actual distance which is manually measured.

\begin{tabular}{|c|c|c|c|c|}
\hline $\begin{array}{l}\text { Image } \\
\text { coordinates } \\
\text { before } \\
\text { movement }\end{array}$ & $\begin{array}{c}\text { Image } \\
\text { coordinates } \\
\text { after } \\
\text { movement }\end{array}$ & $\begin{array}{l}\text { Calculated } \\
\text { distance } \\
(\mathrm{mm})\end{array}$ & $\begin{array}{l}\text { Actual } \\
\text { distance } \\
(\mathrm{mm})\end{array}$ & $\begin{array}{l}\text { Deviation } \\
\quad(\mathrm{mm})\end{array}$ \\
\hline$(455,220)$ & $(450,345)$ & 698.6 & 700 & -1.4 \\
\hline$(492,224)$ & $(486,348)$ & 701.3 & 700 & 1.3 \\
\hline$(501,227)$ & $(494,351)$ & 701.5 & 700 & 1.5 \\
\hline$(520,251)$ & $(513,374)$ & 701.1 & 700 & 1.1 \\
\hline$(526,247)$ & $(518,370)$ & 698.5 & 700 & -1.5 \\
\hline$(534,252)$ & $(526,374)$ & 700.8 & 700 & 0.8 \\
\hline$(547,249)$ & $(539,372)$ & 700.0 & 700 & 0 \\
\hline$(551,248)$ & $(542,371)$ & 701.8 & 700 & 1.8 \\
\hline$(330,277)$ & $(335,402)$ & 700.9 & 700 & 0.9 \\
\hline$(474,239)$ & $(468,363)$ & 699.1 & 700 & -0.9 \\
\hline$(501,231)$ & $(495,355)$ & 701.3 & 700 & 1.3 \\
\hline$(513,240)$ & $(505,362)$ & 699.0 & 700 & -1 \\
\hline$(520,246)$ & $(513,369)$ & 701.4 & 700 & 1.4 \\
\hline$(528,254)$ & $(521,376)$ & 701.8 & 700 & 1.8 \\
\hline$(529,260)$ & $(522,382)$ & 702.2 & 700 & 2.2 \\
\hline$(535,255)$ & $(527,378)$ & 701.1 & 700 & 1.1 \\
\hline$(535,259)$ & $(527,382)$ & 701.0 & 700 & 1 \\
\hline$(540,257)$ & $(532,380)$ & 701.1 & 700 & 1.1 \\
\hline$(513,240)$ & $(505,362)$ & 698.4 & 700 & -1.6 \\
\hline$(501,225)$ & $(494,349)$ & 700.3 & 700 & 0.3 \\
\hline
\end{tabular}

It is shown in Table 5 that in the experiment of Nanjing Steel Plant, the biggest deviation of our method from singlewire measurement method is $6.4 \mathrm{~mm}$ and the mean deviation of our method from single-wire measurement method is $2.1 \mathrm{~mm}$, and in the experiment of Nanjing Steel Plant, the biggest deviation of our method from double-wire measurement method is $7.6 \mathrm{~mm}$ and the mean deviation of our method from double-wire measurement method is $3.0 \mathrm{~mm}$.

From Tables 4 and 5, we can conclude that our instrumentation and measurement method can accurately measure the TCF thickness, and our method has higher measurement precision and even can replace single/double wire measurement methods in continuous casting steelmaking process.

It is shown in Figures 17 and 18 that these three groups of measured results (our method, single-wire measurement method, and double-wire measurement method) have similar trend. As time went by, the TCF was melted by the molten steel on and on; therefore, the TCF thickness became thinner and thinner until the operator added one more bag of TCF through the tundish hole. The operator added TCF every two hours (at 2, 4, 6, and 8 hours in Figures 17 and 18); therefore, the TCF thickness became much thicker after the TCF was added.

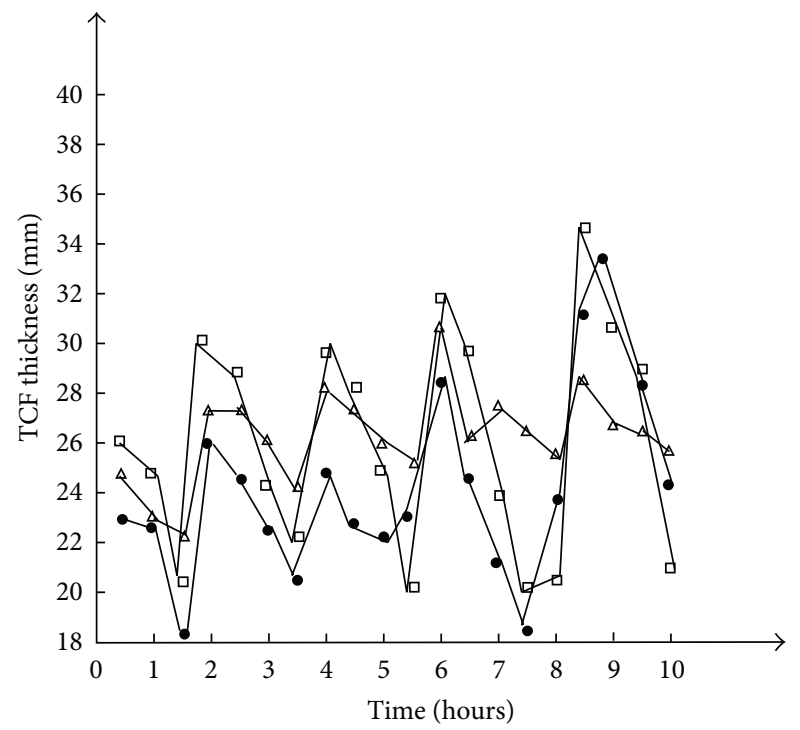

Figure 17: Measurement results and comparison between our method and the traditional single/double wire measurement methods. All these data were obtained from Sanming Steel Plant. $\square$ represents the results of our method, - represents the results of single-wire measurement method, and $\Delta$ represents the results of double-wire measurement method.

\section{Conclusion}

This paper presents a novel measurement method and instrumentation to measure the thickness of TCF in continuous casting steelmaking process. The method is based on computer vision algorithms and the instrumentation is specifically designed and built, which was composed of a measurement bar, a mechanical device, a high-definition industrial camera, a PLC, and a computer. Experiments and results showed that our measurement method and instrumentation can accurately measure the thickness of TCF in continuous casting steelmaking process and had good safety for operators. Furthermore, our measurement method and instrumentation can replace traditional single/double wire measurement methods.

\section{Appendix}

The proof of transformation from image coordinates to world coordinates

$\because$ Point $I$ is the joint point of optical

center $O$ on the plane $A B U$

$\therefore$ Line $O I \perp$ plane $A B U$

$\therefore$ Plane $O G I \perp$ plane $A B U$

$\because$ Line $J G \perp$ line $E F$

$\therefore$ Line $J G \perp$ plane $O G I$.

Suppose that point $P$ is any point on the plane $A B C D$, whose world coordinate is $\left(P_{x}, P_{y}\right)$. And the corresponding point of 
TABLE 3: Main ingredient of the TCF.

\begin{tabular}{lcccccccc}
\hline Ingredient & $\mathrm{SiO}_{2}$ & $\mathrm{MnO}$ & $\mathrm{Al}_{2} \mathrm{O}_{3}$ & $\mathrm{CaO}$ & $\mathrm{MgO}$ & $\mathrm{FeO}$ & $\mathrm{Fe}_{2} \mathrm{O}_{3}$ & $\mathrm{P}_{2} \mathrm{O}_{5}$ \\
Content (\%) & $11.7-15$ & $3.1-4$ & $1-1.6$ & $49-53$ & $3.1-10$ & $11-17$ & $6.9-8$ & $1.7-2$ \\
\hline
\end{tabular}

TABLE 4: Measurement results and comparison between our method and the traditional single/double wire measurement methods. All these data were obtained from Sanming Steel Plant.

\begin{tabular}{|c|c|c|c|c|}
\hline $\begin{array}{l}\text { TCF thickness } \\
\text { measured by our } \\
\text { method }(\mathrm{mm})\end{array}$ & $\begin{array}{l}\text { TCF thickness measured } \\
\text { by single-wire } \\
\text { measurement method } \\
\text { from operator no. } 1(\mathrm{~mm})\end{array}$ & $\begin{array}{l}\text { TCF thickness measured } \\
\text { by double-wire } \\
\text { measurement method } \\
\text { from operator no. } 2(\mathrm{~mm})\end{array}$ & $\begin{array}{l}\text { Deviation of our method } \\
\text { from single-wire } \\
\text { measurement method }(\mathrm{mm})\end{array}$ & $\begin{array}{l}\text { Deviation of our method } \\
\text { from double-wire } \\
\text { measurement method (mm) }\end{array}$ \\
\hline 26.1 & 23.9 & 24.8 & 2.2 & 1.3 \\
\hline 24.8 & 23.3 & 23.5 & 1.5 & 1.3 \\
\hline 20.7 & 18.8 & 22.1 & 1.9 & -1.4 \\
\hline 30.5 & 26.1 & 27.6 & 4.4 & 2.9 \\
\hline 29.1 & 24.6 & 27.6 & 4.5 & 1.5 \\
\hline 24.9 & 22.8 & 26.1 & 2.1 & -1.2 \\
\hline 22.8 & 21.8 & 24.1 & 1 & -1.3 \\
\hline 29.8 & 25.1 & 28.3 & 4.7 & 1.5 \\
\hline 28.6 & 22.9 & 27.3 & 5.7 & 1.3 \\
\hline 25.7 & 22.5 & 26.1 & 3.2 & -0.4 \\
\hline 20.5 & 23.6 & 25.3 & -3.1 & -4.8 \\
\hline 32.9 & 28.8 & 30.8 & 4.1 & 2.1 \\
\hline 29.8 & 25.3 & 26.2 & 4.5 & 3.6 \\
\hline 24.3 & 21.8 & 27.5 & 2.5 & -3.2 \\
\hline 20.9 & 18.5 & 26.5 & 2.4 & -5.6 \\
\hline 20.8 & 23.9 & 25.8 & -3.1 & -5 \\
\hline 35.1 & 31.8 & 28.8 & 3.3 & 6.3 \\
\hline 31.6 & 33.4 & 26.9 & -1.8 & 4.7 \\
\hline 29.1 & 28.4 & 26.6 & 0.7 & 2.5 \\
\hline 21.0 & 24.4 & 25.8 & -3.4 & -4.8 \\
\hline Biggest deviation & & & 5.7 & 6.3 \\
\hline Mean deviation & & & 3.0 & 2.8 \\
\hline
\end{tabular}

$P$ in the image is $P^{\prime}$, whose image coordinate is $\left(p_{x}, p_{y}\right)$. As shown in Figure 7, point $P$ and point $Q$ have the same vertical coordinate, which is $G Q$. Therefore, corresponding point of $Q$ in the image is $Q^{\prime}$, and $Q^{\prime} G^{\prime}=p_{y}$, which shown in Figure 19:

$$
\begin{aligned}
& \operatorname{tg} \alpha=\frac{G^{\prime} Q^{\prime}}{O G^{\prime}}=\frac{p_{y}}{G^{\prime} E^{\prime} / \operatorname{tg}\left(\angle G^{\prime} O E^{\prime}\right)} \\
&=\frac{p_{y}}{(1 / 2) H / \operatorname{tg} \alpha_{0}} \\
&=\frac{2 p_{y} \times \operatorname{tg} \alpha_{0}}{H} \\
& \therefore \alpha=\operatorname{arctg} \frac{2 p_{y} \times \operatorname{tg} \alpha_{0}}{H} .
\end{aligned}
$$

Similarly,

$$
\beta=\operatorname{arctg} \frac{2 p_{x} \times \operatorname{tg} \beta_{0}}{W}
$$

$H$ represents the height of the image:

$$
\begin{aligned}
O G & =\frac{h}{\cos \gamma_{0}} \\
\because I G & =h \times \operatorname{tg} \gamma_{0} \\
I Q & =h \times \operatorname{tg}\left(\gamma_{0}+\alpha\right) \\
\therefore G Q & =I Q-I G=h\left(\operatorname{tg}\left(\gamma_{0}+\alpha\right)-\operatorname{tg} \gamma_{0}\right) \\
\therefore P_{y} & =G Q=I Q-I G=h\left(\operatorname{tg}\left(\gamma_{0}+\alpha\right)-\operatorname{tg} \gamma_{0}\right) .
\end{aligned}
$$


TABLE 5: Measurement results and comparison between our method and the traditional single/double wire measurement methods. All these data were obtained from the Nanjing Steel Plant.

\begin{tabular}{|c|c|c|c|c|}
\hline $\begin{array}{l}\text { TCF thickness } \\
\text { measured by our } \\
\text { method }(\mathrm{mm})\end{array}$ & $\begin{array}{c}\text { TCF thickness measured } \\
\text { by single-wire } \\
\text { measurement method } \\
\text { from operator no. } 1(\mathrm{~mm})\end{array}$ & $\begin{array}{c}\text { TCF thickness measured } \\
\text { by double-wire } \\
\text { measurement method } \\
\text { from operator no. } 2(\mathrm{~mm})\end{array}$ & $\begin{array}{l}\text { Deviation of our method } \\
\text { from single-wire } \\
\text { measurement method }(\mathrm{mm})\end{array}$ & $\begin{array}{l}\text { Deviation of our method } \\
\text { from double-wire } \\
\text { measurement method }(\mathrm{mm})\end{array}$ \\
\hline 33.5 & 35.8 & 33.6 & -2.3 & -0.1 \\
\hline 31.0 & 31.9 & 30.7 & -0.9 & 0.3 \\
\hline 30.0 & 27.6 & 29.8 & 2.4 & 0.2 \\
\hline 37.6 & 40.3 & 36.1 & -2.7 & 1.5 \\
\hline 35.7 & 39.5 & 33.1 & -3.8 & 2.6 \\
\hline 31.2 & 30.0 & 28.5 & 1.2 & 2.7 \\
\hline 26.5 & 29.1 & 23.8 & -2.6 & 2.7 \\
\hline 40.0 & 40.9 & 37.6 & -0.9 & 2.4 \\
\hline 37.9 & 31.5 & 34.8 & 6.4 & 3.1 \\
\hline 31.0 & 27.6 & 29.7 & 3.4 & 1.3 \\
\hline 21.6 & 25.9 & 28.1 & -4.3 & -6.5 \\
\hline 43.8 & 42.9 & 38.1 & 0.9 & 5.7 \\
\hline 38.5 & 38.7 & 34.6 & -0.2 & 3.9 \\
\hline 28.9 & 31.6 & 30.8 & -2.7 & -1.9 \\
\hline 25.3 & 24.3 & 28.5 & 1 & -3.2 \\
\hline 45.5 & 45.8 & 42.5 & -0.3 & 3 \\
\hline 40.6 & 42.6 & 33.0 & -2 & 7.6 \\
\hline 37.1 & 37.1 & 32.1 & 0 & 5 \\
\hline Biggest deviation & & & 6.4 & 7.6 \\
\hline Mean deviation & & & 2.1 & 3.0 \\
\hline
\end{tabular}

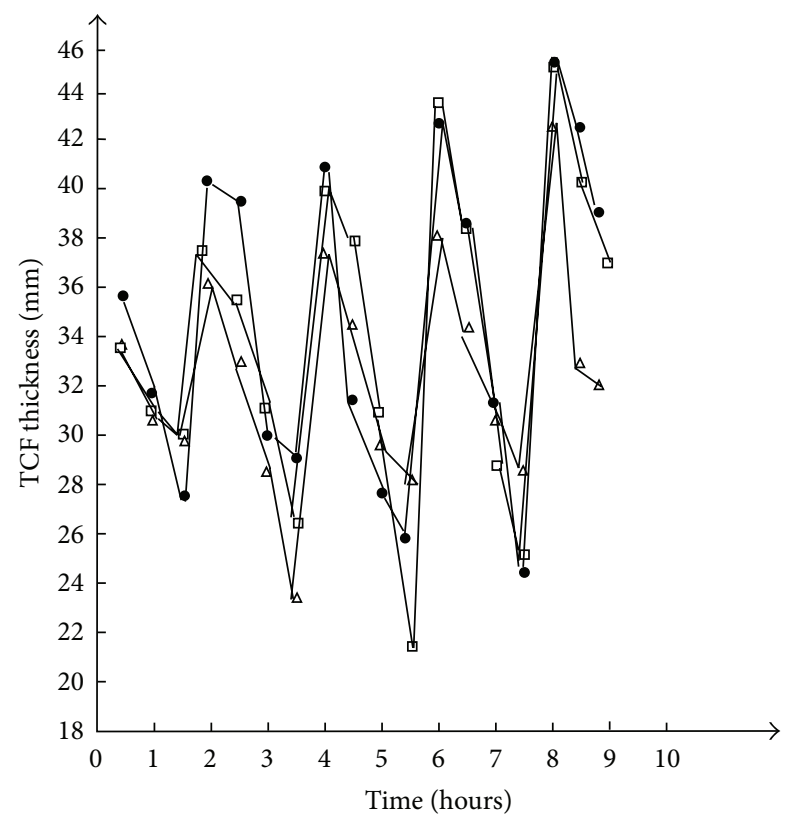

FIGURE 18: Measurement results and comparison between our method and the traditional single/double wire measurement methods. All these data were obtained from Nanjing Steel Plant. $\square$ represents the results of our method, - represents the results of single-wire measurement method, and $\Delta$ represents the results of double-wire measurement method.

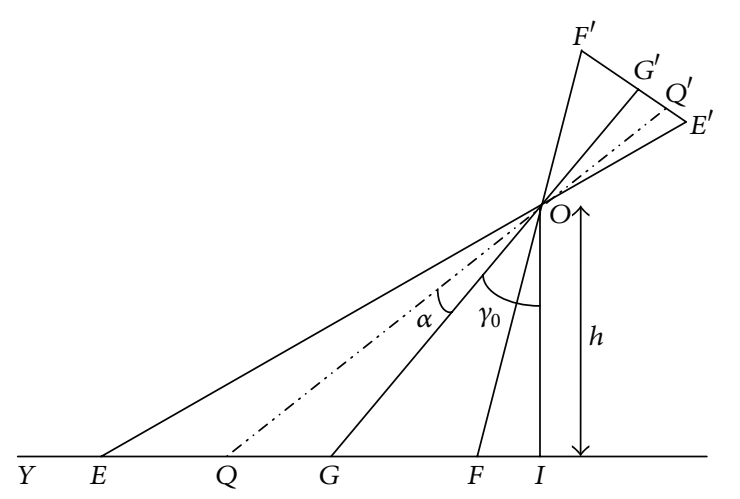

FIGURE 19: Schematic diagram of the corresponding point vertical coordinate between the world coordinates system and the image coordinates system. Point $Q$ has the same vertical coordinate with the point $P$ in the plane $A B C D$, and the corresponding point of point $Q$ in the image is point $Q^{\prime}$, and $Q^{\prime} G^{\prime}=p_{y}$.

From formula (A.6), the vertical coordinate of point $P$ in the world coordinates system can be obtained from the image coordinate system: 
$\because I G=h \times \operatorname{tg} \gamma_{0}$

$$
\begin{aligned}
I F & =h \times \operatorname{tg}\left(\gamma_{0}-\alpha_{0}\right) \\
\therefore G F & =I G-I F=h \times\left(\operatorname{tg} \gamma_{0}-\operatorname{tg}\left(\gamma_{0}-\alpha_{0}\right)\right) \\
\because O G & =\frac{h}{\cos \gamma_{0}} \\
O F & =\frac{h}{\cos \left(\gamma_{0}-\alpha_{0}\right)}
\end{aligned}
$$

and $F C / / G J, J G \perp$ plane $O G I$

$$
\begin{aligned}
& \therefore F C \perp \text { plane } O G I \\
& \therefore G J=O G \times \operatorname{tg} \beta_{0}=\frac{h}{\cos \gamma_{0}} \times \operatorname{tg} \beta_{0} \\
& F C=O F \times \operatorname{tg} \beta_{0}=\frac{h}{\cos \left(\gamma_{0}-\alpha_{0}\right)} \times \operatorname{tg} \beta_{0} \\
& \because \triangle U F C \backsim \triangle U G J \\
& \therefore \frac{F C}{G J}=\frac{U F}{U G} \\
& \therefore \frac{F C-G J}{G J}=\frac{U F-U G}{U G}=\frac{-G F}{U G} \\
& \therefore U G=\frac{G J \times G F}{G J-F C}=\frac{h\left[\operatorname{tg} \gamma_{0}-\operatorname{tg}\left(\gamma_{0}-\alpha_{0}\right)\right] \cos \left(\gamma_{0}-\alpha_{0}\right)}{\cos \left(\gamma_{0}-\alpha_{0}\right)-\cos \gamma_{0}} \\
& \therefore G L=O G \times \operatorname{tg} \beta=\frac{O I}{\cos \gamma_{0}} \times \operatorname{tg} \beta=\frac{h}{\cos \gamma_{0}} \times \operatorname{tg} \beta \\
& \text { In } \triangle U P Q, \frac{G L}{P Q}=\frac{U G}{U Q} \\
& \therefore P Q=\frac{G L(U G+G Q)}{U G} \text {. }
\end{aligned}
$$

$G Q, U G$, and $G L$ can be obtained by formulas (A.6), (A.8), and (A.9), respectively.

Thus,

$$
\begin{aligned}
\therefore P_{x}= & P Q \\
= & \frac{h}{\cos \gamma_{0}} \times \operatorname{tg} \beta \\
& \times\left(1+\frac{\left(\operatorname{tg}\left(\gamma_{0}+\alpha\right)-\operatorname{tg} \gamma_{0}\right) \times\left(\cos \left(\gamma_{0}-\alpha_{0}\right)-\cos \gamma_{0}\right)}{\left(\operatorname{tg} \gamma_{0}-\operatorname{tg}\left(\gamma_{0}-\alpha_{0}\right)\right) \times \cos \left(\gamma_{0}-\alpha_{0}\right)}\right) .
\end{aligned}
$$

From formula (A.11), the horizontal coordinate of point $P$ in the world coordinates system can be obtained from the image coordinate system.
Therefore, the transformation from the image coordinates system $\left(p_{x}, p_{y}\right)$ to the world coordinates system $\left(P_{x}, P_{y}\right)$ is

$$
\begin{aligned}
P_{x}= & \frac{h}{\cos \gamma_{0}} \times \operatorname{tg} \beta \\
& \quad \times\left(1+\frac{\left(\operatorname{tg}\left(\gamma_{0}+\alpha\right)-\operatorname{tg} \gamma_{0}\right) \times\left(\cos \left(\gamma_{0}-\alpha_{0}\right)-\cos \gamma_{0}\right)}{\left(\operatorname{tg} \gamma_{0}-\operatorname{tg}\left(\gamma_{0}-\alpha_{0}\right)\right) \times \cos \left(\gamma_{0}-\alpha_{0}\right)}\right), \\
P_{y}= & h\left(\operatorname{tg}\left(\gamma_{0}+\alpha\right)-\operatorname{tg} \gamma_{0}\right), \\
\alpha= & \operatorname{arctg} \frac{2 p_{y} \times \operatorname{tg} \alpha_{0}}{H}, \\
\beta= & \operatorname{arctg} \frac{2 p_{x} \times \operatorname{tg} \beta_{0}}{W} .
\end{aligned}
$$

\section{Acknowledgments}

This research was supported by the National Natural Science Foundation of China (no. 61101057) and Shenyang Taihe Metallurgical Measurement and Control Ltd.

\section{References}

[1] H. Kania, K. Nowacki, and T. Lis, "Impact of the density of the mould powder on thickness of the layer of liquid slag in the continuous caster mould," Metalurgija, vol. 52, no. 2, pp. 204206, 2013.

[2] H. Kania and J. Gawor, "Impact of mould powder density on surface quality and near-surface zone microstructure of cast slab," Archives of Metallurgy and Materials, vol. 57, no. 1, pp. 339345, 2012.

[3] J. P. Birat, M. Larrecq, and J. Y. Lamant, "The continuous-casting mold-a basic tool for surface quality and strand productivity," in Proceedings of the 74th Steelmaking Division of the Iron and Steel Society, pp. 39-50, 1991.

[4] K.-D. Schmidt, F. Friedel, K.-P. Imlau, W. Jäger, and K. T. Müller, "Consequent improvement of surface quality by systematic analysis of slabs," Steel Research International, vol. 74, no. 11-12, pp. 659-666, 2003.

[5] Z. Hu, Y. Ci, and Z. Xie, "Molten steel level measurement in tundish with heat transfer analysis," ISIJ International, vol. 51, no. 10, pp. 1674-1681, 2011.

[6] Y. Ci, Z. Xie, and H. Zhang, "New approach to continuous temperature measurement of liquid steel in CC tundish," Journal of Northeastern University, vol. 25, no. 5, pp. 460-462, 2004.

[7] H. Zhang and Z. Xie, "Accuracy improvement and structure optimization of continuous temperature measurement sensor for liquid steel," Acta Metrologica Sinica, vol. 29, no. 1, pp. 3841, 2008.

[8] Z. Xie, Y. Ci, H. Meng, and H. Zhang, "Development of continuous temperature measuring sensor for liquid steel based on blackbody cavity," Chinese Journal of Scientific Instrument, vol. 26, no. 5, pp. 446-449, 2005.

[9] H. Zhang and Z. Xie, "Simulation study on dynamic temperature measurement of liquid steel continuous temperature measurement sensor," Chinese Journal of Scientific Instrument, vol. 28, no. 10, pp. 1775-1780, 2007. 
[10] Z. Hua, C. Ying, and X. Zhi, "Dynamic modeling of temperature sensors with great inertia," Chinese Journal of Scientific Instrument, vol. 25, no. 4, pp. 261-264, 2004.

[11] Z. Shumao, M. Guohui, Z. Jiu, and X. Zhi, "Finite element analysis of composite structure continuous temperature-measuring sensor for liquid steel," Journal of Northeastern University (Natural Science), vol. 33, no. 7, pp. 926-929, 2012.

[12] H. Zhang and Z. Xie, "Static and dynamic uncertainty evaluation of continuous temperature measurement system for liquid steel," Acta Metrologica Sinica, vol. 28, no. 4, pp. 329-332, 2007.

[13] H.-J. Meng, R.-Y. Wu, Z. Xie, and G.-Q. Lin, "Casting speed optimization control system based on continuous temperature measurement of molten steel in CC tundish," Journal of Northeastern University (Natural Science), vol. 26, no. 10, pp. 942-945, 2005.

[14] S.-M. Zhao, G.-H. Mei, and Z. Xie, "Effect of MgO critical particle size on properties of $\mathrm{MgO}-\mathrm{C}$ continuous temperaturemeasuring sensor for liquid steel," Journal of Iron and Steel Research International, vol. 18, no. 12, pp. 12-21, 2011.

[15] W. Liu and Z. Xie, "Design and application of dynamic control system for secondary cooling of billet continuous casting," in Proceedings of the IEEE International Conference on Advanced Computer Control (ICACC '10), pp. 230-233, March 2010.

[16] B. Wang, Z.-P. Ji, W.-H. Liu, J.-C. Ma, and Z. Xie, "Application of hot strength and ductility test to optimization of secondary cooling system in billet continuous casting process," Journal of Iron and Steel Research International, vol. 15, no. 4, pp. 16-20, 2008.

[17] W.-H. Liu, Z. Xie, Z.-P. Ji, B. Wang, Z.-Y. Lai, and G.-L. Jia, "Dynamic water modeling and application of billet continuous casting," Journal of Iron and Steel Research International, vol. 15, no. 2, pp. 14-17, 2008.

[18] J. Ma, Z. Xie, and G. Jia, "Applying of real-time heat transfer and solidification model on the dynamic control system of billet continuous casting," ISIJ International, vol. 48, no. 12, pp. 17221727, 2008.

[19] Z. Ji and Z. Xie, "Multi-objective optimization of continuous casting billet based on ant colony system algorithm," in Proceedings of the Pacific-Asia Workshop on Computational Intelligence and Industrial Application (PACIIA '08), pp. 262266, December 2008.

[20] W. Liu, Z. Xie, Z. Ji, and B. Wang, "Research and application of dynamic control system for secondary cooling of billet continuous casting," in Proceedings of the 2nd IEEE Conference on Industrial Electronics and Applications (ICIEA '07), pp. 184187, May 2007.

[21] J. Liu, D. Li, Z. Hu, and Z. Xie, "Monocular computer vision image calibration method and its application," in Proceedings of the IEEE International Conference on Advanced Computer Control (ICACC '10), pp. 144-147, March 2010.

[22] G. Lei, X. Youchun, L. Keqiang, and L. Xiaomin, "Study on realtime distance detection based on monocular vision technique," Journal of Image and Graphics, vol. 11, no. 1, pp. 74-81, 2006.

[23] S. W. Yang, S. A. Scherer, and A. Zell, "An onboard monocular vision system for autonomous takeoff, hovering and landing of a micro aerial vehicle," Journal of Intelligent \& Robotic Systems, vol. 69, no. 1-4, pp. 499-515, 2013.

[24] D. G. Lowe, "Object recognition from local scale-invariant features," in Proceedings of the 7th IEEE International Conference on Computer Vision (ICCV'99), pp. 1150-1157, September 1999.
[25] D. G. Lowe, "Distinctive image features from scale-invariant keypoints," International Journal of Computer Vision, vol. 60, no. 2, pp. 91-110, 2004. 


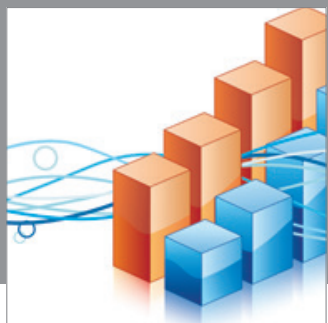

Advances in

Operations Research

mansans

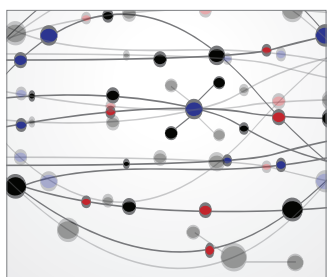

The Scientific World Journal
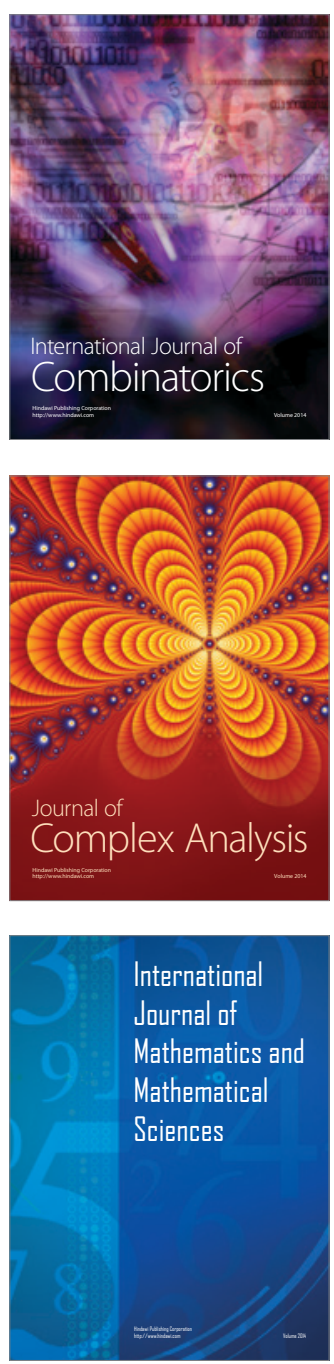
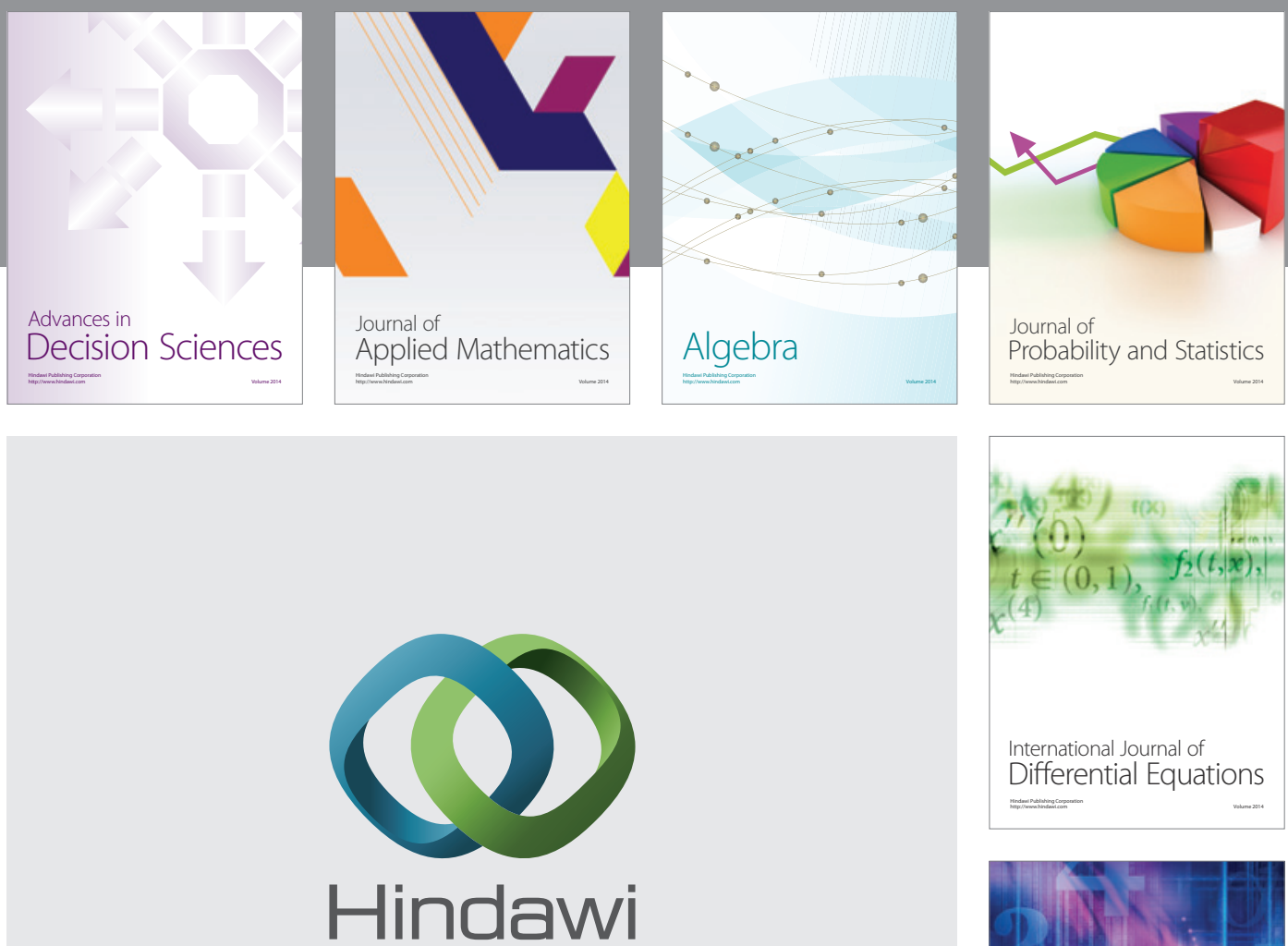

Submit your manuscripts at http://www.hindawi.com
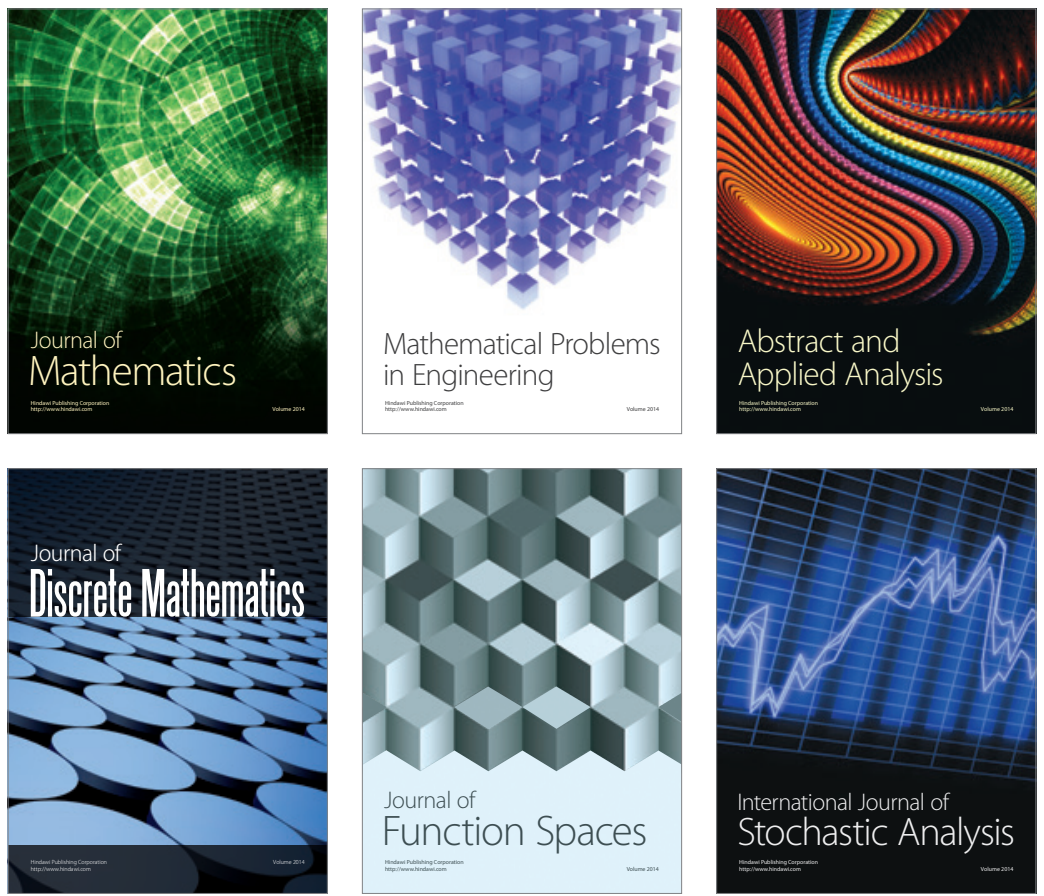

Journal of

Function Spaces

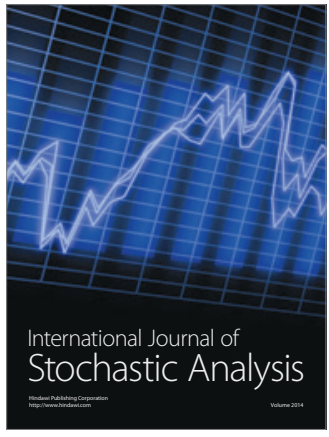

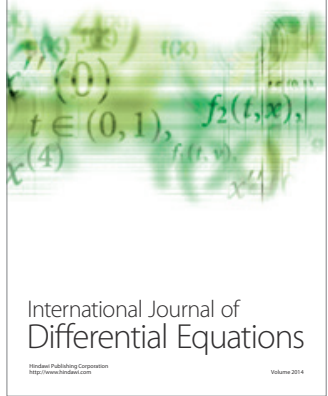
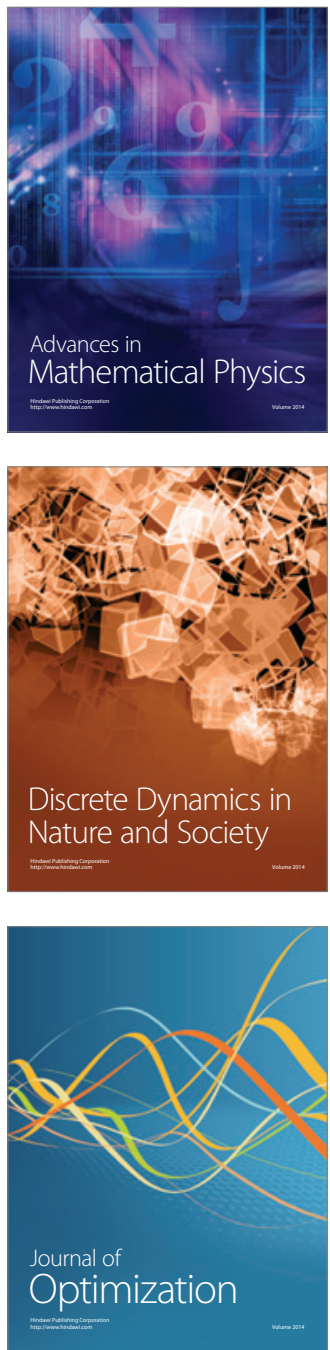